Article

\title{
Screening for the Proteins That Can Interact with Grouper Nervous Necrosis Virus Capsid Protein
}

\author{
Po-Yu Huang ${ }^{1,+}{ }^{+}$Han-Chia Hsiao ${ }^{2,+}$, Szu-Wen Wang ${ }^{2}$, Shao-Fu Lo ${ }^{2}{ }^{-}$, Ming-Wei Lu ${ }^{3}$ and \\ Li-Li Chen ${ }^{1,2, *}$ \\ 1 Center of Excellence for the Oceans, National Taiwan Ocean University, No. 2, Pei-Ning Road, \\ Keelung 20224, Taiwan; abcm1042@hotmail.com \\ 2 Institute of Marine Biology, National Taiwan Ocean University, No. 2, Pei-Ning Road, Keelung 20224, Taiwan; \\ elly010042@gmail.com (H.-C.H.); wen810722@hotmail.com (S.-W.W.); john81john81@yahoo.com.tw (S.-F.L.) \\ 3 Department of Aquaculture, National Taiwan Ocean University, No. 2, Pei-Ning Road, \\ Keelung 20224, Taiwan; mingwei@mail.ntou.edu.tw \\ * Correspondence: joechen@ntou.edu.tw \\ + These authors contributed equally to this work.
}

Received: 17 August 2020; Accepted: 1 September 2020; Published: 4 September 2020

\begin{abstract}
Nervous necrosis virus (NNV) can infect many species of fish and has an 80-100\% mortality rate. NNV capsid protein (NNVCP) is the only structural protein of NNV, but there are few studies on the protein-protein interaction between NNVCP and the host cell. To investigate NNV morphogenesis, native NNV capsid protein (NNVCP) was used to screen for protein-protein interactions in this study. The results identified that 49 grouper optic nerve proteins can interact with NNVCP and may function as putative receptor or co-receptor, cytoskeleton, glucose metabolism and ATP generation, immunity, mitochondrial ion regulation, and ribosomal proteins. Creatine kinase B-type (CKB) is one of those 49 optic nerve proteins. CKB, a kind of enzyme of ATP generation, was confirmed to interact with NNVCP by far-Western blot and showed to colocalize with NNVCP in GF-1 cells. Compared to the control, the expression of CKB was significantly induced in the brain and eyes infected with NNV. Moreover, the amount of replication of NNV is relatively high in cells expressing CKB. In addition to providing the database of proteins that can interact with NNVCP for subsequent analysis, the results of this research also verified that $\mathrm{CKB}$ plays an important role in the morphogenesis of NNV.
\end{abstract}

Keywords: nervous necrosis virus; immunoprecipitation assay; protein-protein interaction; creatine kinase; far-Western blot

\section{Introduction}

Grouper is an aquaculture fish with substantial economic value and it is an important source of income in many Asian countries. Like other high-density aquaculture species, groupers are also threatened by many pathogens, including Vibrio alginolyticus, iridovirus, and nervous necrosis virus (NNV) [1-4]. NNV is highly lethal to all grouper stages and results in massive economic losses worldwide [5]. NNV is the causative agent of viral nervous necrosis (VNN) disease, which has a wide host range, infecting at least 40 families of fish species [6-10]. NNV infects the central nervous system and causes vacuolation of the brain and retina [11]. NNV has a non-enveloped icosahedral structure and belongs to the family Nodaviridae (genus Betanodavirus), and its genome consists of two single-stranded positive-sense RNAs. RNA1 encodes the RNA-dependent RNA polymerase (RdRp), and RNA2 encodes the viral capsid protein [12-16]. The NNV capsid protein (NNVCP) is the only structural protein of the virion and has been shown to determine the host range [17]. Betanodaviruses have been classified into the following four genotypes based on the sequence of the RNA2 segment: 
tiger puffer NNV (TPNNV), striped jacked NNV (SJNNV), red-spotted grouper NNV (RGNNV), and barfin flounder NNV (BFNNV) [18]. Despite its relatively simple virion structure, no clear NNV receptor has been identified, and the mechanism of NNV infection remains unclear.

It is very difficult to prevent NNV in the aquaculture process except through preventing infection by parental fish, ensuring water quality, and actively managing feed and livestock. NNV is very contagious, and it is difficult to completely eliminate NNV from aquaculture environments. DNA vaccines, interferons, or immunostimulants can be used to reduce NNV infections and outbreaks, but they are not sufficient to completely control the epidemic [19-22]. However, the functional roles of host factors interacting with the NNVCP in viral genome replication remain ambiguous.

Although NNV can infect more than 30 marine and freshwater fish species, and furthermore, NNV capsid protein (NNVCP) was the only external viral structural protein in virus particles, to date, only GHSC70 and MmHSP90ab1 have been identified as attachment receptors for NNV [23,24]. However, preventing these proteins from interacting with cells cannot inhibit viral infection, so NNV is thought to still have other undiscovered host receptors or co-receptors. In addition, many cellular proteins that may be involved in the NNV morphogenesis have not been verified. Thus, native NNVCP isolated from the grouper cell line GF-1, rather than a recombinant protein generated by bacteria, was applied in this study to investigate the proteins that can interact with NNVCP. Optic nerves were selected from uninfected orange-spotted grouper (Epinephelus coioides) to evaluate protein interactions with native NNVCP by immunoprecipitation (IP). We annotated the proteins using 1DLC, LTQ-Orbitrap MS database of the Epinephelus genus in NCBI and UniProt. The 49 identified proteins could contribute as putative receptor or co-receptor, cytoskeleton, glucose metabolism, and ATP generation, immunity, mitochondrial ion regulation, and ribosomal proteins.

The virus uses the energy of the host cell to complete its morphogenesis. In the early stage of NNV infection, viral replication leads the host cell to rapidly deplete ATP; then, NNV uses grouper voltage-dependent anion channel 2 (GVDAC2) to maintain the sufficient ATP for NNV RNA synthesis [25]. Since there are many energy-generating mechanisms in cells, in this study, we investigated the role of creatine kinase (CK), another molecule that catalyzes energy production, during NNV infection. Far-Western blot and cellular colocalization analysis confirmed that creatine kinase brain type (CKB) can interact with $\mathrm{NNVCP}$, and it was observed that $\mathrm{CKB}$ can enhance NNV replication in GF-1 cells. In addition to providing more information about the types of cellular proteins that can bind to NNV, this study also confirmed that enzymes that contribute to cellular ATP generation, such as $\mathrm{CK}$, provide assistance in the morphogenesis of NNV.

\section{Materials and Methods}

\subsection{Cell Line and Cell Transfection}

The grouper fin cell line (GF-1, BCRC 960094) was obtained from the Bioresource Collection and Research Center (BCRC) in Taiwan. Cell culture was performed according to the work of Chang and Chi [23]. Briefly, cells were cultured in Leibovitz's L-15 medium (Thermo Fisher Scientific Inc., Waltham, MA, USA) with $5 \%$ fetal bovine serum (FBS) (Thermo Fisher Scientific) and maintained at $27^{\circ} \mathrm{C}$. Transfection was performed in a 24-well format. About $1 \times 10^{5}$ cells were seeded in each well of the 24-well culture plate and cultured overnight. The CK B-type was amplified from orange-spotted groupers (Epinephelus coioides) optic nerve cDNA with the following primer set CKB-F/CKB-R (5'-CAGG GGGATCCCATGCCTTTCGGTAA-3'/GTCAGGGAATTCTTACTTCTGGGCGGG, the underlined bases indicate the $B a m H I$ and $E c o$ RI restriction sites for gene cloning). The resultant recombinant plasmid, pcDNA3-CKB plasmid, was mixed with Lipofectamine 2000 kit (Thermo Fisher Scientific) in the medium and laid over the cultured cells according to the manufacturer's recommendations. Two days after transfection, the cells were cultured in selective medium contained with geneticin (G418) (Thermo Fisher Scientific) $(400 \mu \mathrm{g} / \mathrm{mL})$. The selective medium was replaced every three days. 


\subsection{Expression and Purification of Recombinant NNVCP and CK B-type, and Antibody Preparation}

Full-length recombinant NNVCP (rNNVCP) and CK B-type (rCKB) were generated using the pET28b+ system. The sequence encoding NNVCP protein was amplified from NNV cDNA with the following primer set: NNVCP-F/NNVCP-R (5'-CGAATTCATGGTACGCAAAGGTGA AAAGA-3'/5'-ATAGTCGACTTAGTTTTCCGAGTCAACCCT-3' , the underlined bases indicate the EcoRI and SalI restriction sites for gene cloning); the CK B-type was amplified from orange-spotted groupers optic nerve cDNA with the following primer set: CKB-F/CKB-R (5'-CAGGGGGATCC CATGCCTTTCGGTAA-3'/GTCAGGGAATTCTTACTTCTGGGCGGG), the underlined bases indicate the BamHI and EcoRI restriction sites for gene cloning). The resultant recombinant plasmid, pET28b-NNVCP and pET28b-CKB, was transformed into the Escherichia coli BL21 (DE3) strain. E. coli BL21 (DE3) cells were cultured in LB medium with $25 \mu \mathrm{g} / \mathrm{mL}$ kanamycin, and the protein was induced with $1 \mathrm{mM}$ isopropyl- $\beta$-D-thiogalactopyranoside (IPTG). Recombinant proteins tagged with six consecutive histidines were purified by QIAexpressionist nickel-nitrilotriacetic acid (Ni-NTA) metal-affinity chromatography (Qiagen, Hilden, Germany) according to the manufacturer's recommendations. The resins were washed with buffer $(\mathrm{pH}$ 8.0) containing $50 \mathrm{mM}$ sodium phosphate, $0.3 \mathrm{M}$ sodium chloride and $10 \mathrm{mM}$ imidazole and eluted with buffer $(\mathrm{pH} 8.0)$ containing $50 \mathrm{mM}$ sodium phosphate, $0.3 \mathrm{M}$ sodium chloride, and $250 \mathrm{mM}$ imidazole. The eluted protein was then concentrated using Amicon Ultra-15 centrifugal filters (Merck Millipore, Burlington, MA, USA) in PBS buffer and stored at $4{ }^{\circ} \mathrm{C}$ for subsequent antiserum production.

Rats were selected to produce the NNVCP-specific polyclonal antibodies. In brief, rats were hyperimmunized by injection with $250 \mu \mathrm{g}$ rNNVCP proteins emulsified in complete Freund's adjuvant. Subsequent booster injections were carried out with $250 \mu \mathrm{g}$ protein emulsified in incomplete Freund's adjuvant every two weeks. Antisera were collected after the antibody titer had peaked.

\subsection{Virus Infection}

NNV was isolated from grouper larvae with NNV disease. NNV was propagated in GF-1 cells at a multiplicity of infection (MOI) of 10, and infected cells were incubated in L-15 medium with $2 \% \mathrm{FBS}$ at $27^{\circ} \mathrm{C}$ for three days until cytopathic effect (CPE) was observed. After CPE was observed, the culture supernatant was collected and centrifuged at $12,000 \mathrm{rpm}$ for $5 \mathrm{~min}$ at $4{ }^{\circ} \mathrm{C}$ and then kept as the virus stock. To further collect cell lysate, $2 \mathrm{~mL}$ of PBS were used to wash cells, and the virus-infected cells were then treated with lysis buffer $(150 \mathrm{mM} \mathrm{NaCl}, 1 \mathrm{mM}$ EDTA, $50 \mathrm{mM}$ Tris-HCl, $0.1 \% \mathrm{NP}-40$, and $0.02 \%$ protease inhibitor, $\mathrm{pH} 8$ ). After slow shaking for $30 \mathrm{~min}$ at $4{ }^{\circ} \mathrm{C}$, the cell lysate was collected in a $1.5 \mathrm{~mL}$ microcentrifuge tube, sonicated for $2 \mathrm{~min}$, and then centrifuged at 12,000 rpm for $10 \mathrm{~min}$ at $4{ }^{\circ} \mathrm{C}$. The supernatant was collected in a new $1.5 \mathrm{~mL}$ microcentrifuge tube and stored at $-20^{\circ} \mathrm{C}$.

\subsection{Grouper Tissue Lysates Preparation}

Uninfected one-year-old orange-spotted groupers were used in the current study; optic nerves were collected and stored in liquid nitrogen. The collected tissue was transferred to a pre-cooled mortar and pestle, and $1 \mathrm{~mL}$ of lysis buffer was then added for careful homogenization on ice. The sample was then transferred to a $1.5 \mathrm{~mL}$ microcentrifuge tube and stored at $-20^{\circ} \mathrm{C}$.

\subsection{SDS-PAGE}

A discontinuous electrophoresis buffer system with a $4 \%$ stacking gel and $12 \%$ resolving gel was used for protein separation. All samples were boiled for $10 \mathrm{~min}$ after the addition of sample loading buffer and subsequently electrophoresed at a voltage of $80 \mathrm{~V}$ for the stacking gel and $120 \mathrm{~V}$ for the resolving gel until the bromophenol blue reached the bottom of the gels. Protein bands were visualized by staining with Coomassie Brilliant Blue R-250. 


\subsection{Western Blot Analyses}

For Western blotting analyses, proteins separated by SDS-PAGE were transferred onto a polyvinylidene difluoride (PVDF) membrane (Merck Millipore) by semi-dry blotting. Membranes were blocked in $5 \%$ skim milk (Difco Laboratories, Sparks, MD, USA) in TBS $(0.2 \mathrm{M} \mathrm{NaCl}$ and $50 \mathrm{mM}$ Tris- $\mathrm{HCl}$, $\mathrm{pH}$ 7.4). Immunodetection was performed by incubating the blot in rat anti-NNVCP protein serum diluted 1:10,000 in TBS with 5\% skim milk for $1 \mathrm{~h}$ at room temperature. Subsequently, goat anti-rat IgG antibody conjugated with horseradish peroxidase (Sigma-Aldrich, St. Louis, MO, USA) was used at a concentration of 1:10,000, and detection was performed with a Western Blot Chemoluminescence Reagent (NEN Life Sciences, Boston, MA, USA).

\subsection{Immunoprecipitation (IP) Assay}

Native NNVCP was produced by NNV-infected GF-1 cells. The virus infection and cell lysate collection methods were described previously. After the cell lysate was collected, $500 \mu \mathrm{L}$ of cell lysate and $1 \mu \mathrm{L}$ of antibody were thoroughly mixed and incubated overnight at $4{ }^{\circ} \mathrm{C}$ under gentle agitation or rotation. $30 \mu \mathrm{L}$ of Protein A agarose beads were added to the mixture and incubated for $4 \mathrm{~h}$ at $4^{\circ} \mathrm{C}$ by gentle mixing on a suitable shaker. After incubation, $300 \mu \mathrm{L}$ of grouper tissue supernatant were added and incubated overnight at $4{ }^{\circ} \mathrm{C}$ on a shaker. $1 \mathrm{~mL}$ of lysis buffer was added to the mixture by maintaining gentle agitation and then centrifuged at $6000 \mathrm{rpm}$ for $3 \mathrm{~min}$ at $4{ }^{\circ} \mathrm{C}$. Lastly, the supernatant was discarded, and the proteins captured by Protein A beads were preliminarily identified by Western blot. The preliminary identified proteins were further analyzed and annotated by 1DLC, LTQ-Orbitrap MS (BIOTOOLS, New Taipei City, Taiwan). The proteins combined with Protein A beads as a control group.

\subsection{CK Amino Acid Sequence Analyses and Phylogenetic Construction}

The CK complete coding sequence was compared with the GenBank database using the program BlastX. Amino acid sequences of six CK B-type and six M-type isolated from other fish animals were retrieved from GenBank, and were used for sequence alignment and phylogenetic analyses. The complete coding sequences of these CK were subsequently subjected to phylogenetic analyses and were performed with Mega4.0 software using the neighbor-joining algorithm. One thousand bootstrap replicates were generated to test the robustness of the trees. Sequences used in the alignment analyses and phylogenetic tree, followed by their GenBank accession number, were Poecilia reticulata (XM_017302257.1), Xiphophorus maculatus (XM_023348108.1), Takifugu rubripes (XM_003971402), Stegastes partitus (XM_008298910.1), Danio rerio (XM_005156643.4), and Oreochromis niloticus (XM_005453435.4).

\subsection{Far-Western Blot Assay}

Rabbit anti-Ckba antibody which is specific to CK B-type was bought from a commercial company (GeneTex, Irvine, CA, USA). The target proteins were separated by SDS-PAGE, transferred to a PVDF membrane, and renatured gradually at $4{ }^{\circ} \mathrm{C}$ overnight in HEPES buffer $(20 \mathrm{mM}$ HEPES, $100 \mathrm{mM}$ $\mathrm{NaCl}, 1 \mathrm{mM}$ EDTA, $1 \mathrm{mM}$ dithiothreitol, $0.1 \%$ Tween 20,10\% glycerol, $\mathrm{pH} 7.5$ ) containing $5 \%$ skim milk. The blot was washed and incubated with $40 \mu \mathrm{g}$ binding protein (rCKB protein) in $10 \mathrm{~mL}$ incubation buffer $(20 \mathrm{mM}$ Tris/ $\mathrm{HCl}, 150 \mathrm{mM} \mathrm{NaCl}, 0.05 \%$ Tween 20,3\% skim milk, $\mathrm{pH} 7.5)$ for $2 \mathrm{~h}$ at room temperature. Then, the blot was incubated in a rabbit anti-Ckba antibody of binding proteins diluted 1:5000 in TBST with 5\% skim milk for $1 \mathrm{~h}$ at room temperature. Subsequently, goat anti-rabbit IgG antibody conjugated with horseradish peroxidase (Jackson ImmunoResearch, West Grove, PA, USA) was used at a concentration of 1:5000 and detection was performed with a Western Lightning ${ }^{\mathrm{TM}}$ Plus-ECL (Bioman, New Taipei City, Taiwan). 


\subsection{Cellular Colocalization of NNVCP and CKB by Indirect Immunofluorescence Assay}

GF-1 cells were first transfected with pcDNA3-CKB for two days and then infected with NNV for one day. After transfection and infection, GF-1 cells were rinsed three times with PBS and then were fixed in paraformaldehyde $\left(4 \%\right.$ in PBS) for $10 \mathrm{~min}$ at $4{ }^{\circ} \mathrm{C}$. After fixation, the solution was replaced with buffer ( $0.1 \%$ Triton X-100, 4\% paraformaldyhyde in PBS) for $3 \mathrm{~min}$; then, the cells were washed three times with PBS and incubated with blocking buffer (5\% bovine serum albumin and 5\% normal goat serum in PBS) for $1 \mathrm{~h}$ at room temperature. The GF-1 cells were then treated with polyclonal rat anti-NNVCP antibody (1:200 in blocking buffer) and rabbit anti-Ckba (1:500 in blocking buffer) for $2 \mathrm{~h}$ at room temperature. Next, the cells were washed three times with PBST (0.2\% Tween-20 in PBS) and reacted with Cy3-conjugated goat anti-rabbit IgG antibodies (1:1000 in PBS; Jackson ImmunoResearch) and anti-rat antibody (1:1000 in PBS; Alexa flour 488) at room temperature. Counterstaining of the nucleus was performed with DAPI. After being washed three times with PBST, the cover glasses were wet mounted and the fluorescent signals were examined with a Leica TCS SP5 Confocal Spectral Microscope Imaging System.

\subsection{Cell Transfection}

To study the function of genes in vitro, cell transfection was conducted using transfection reagent Lipofectamine 2000. Briefly, GF-1 cells were seeded in six-well cell culture plates at $60-70 \%$ confluence. The next day, cells were transfected by addition of the mixture of Lipofectamine 2000 and plasmids following the manufacturer's instructions. Six hours after the transfection, the transfection medium was replaced with the fresh normal medium and cells were cultured at $27^{\circ} \mathrm{C}$ for further study. Two days after transfection, the cells were infected for three days and were then collected for further study.

\subsection{RNA Extraction and qRT-PCR Analysis}

Tissues $(100 \mu \mathrm{g})$ were homogenized in $1 \mu \mathrm{L}$ of TRIzol reagent (Thermo Fisher Scientific) and then subjected to 2-propanol extraction and ethanol precipitation according to the manufacturer's recommendations. Total RNA was centrifuged in $75 \%$ ethanol at $14,000 \times g$ for $30 \mathrm{~min}$ at room temperature. The pellet was dissolved in DEPC-water and quantified by spectrophotometry. After RNA extraction, $1 \mu \mathrm{g}$ of total RNA was used for cDNA synthesis using HiScript I Reverse Transcriptase (BIONOVAS, Toronto, ON, Canada). Reverse transcription was conducted according to the manufacturer's protocol with an Oligo (dT)18 primer. The synthesis condition of cDNA was set at: $65{ }^{\circ} \mathrm{C}$ for $5 \mathrm{~min}, 42{ }^{\circ} \mathrm{C}$ for $60 \mathrm{~min}$, and $70{ }^{\circ} \mathrm{C}$ for $15 \mathrm{~min}$. Quantitative real-time PCR (qPCR) was performed using the Applied Biosystem ${ }^{\mathrm{TM}} 7500$ Real-Time PCR System (Applied Biosystems, Waltham, MA, USA) on a TOptical Thermocycler ®(Analytik Jena AG, Jena, Germany). The qPCR reaction contains $1 \mu \mathrm{L}$ of the cDNA template, $10 \mu \mathrm{L}$ of the $2 \times$ qPCRBIO syGreen Master Mix, and $0.8 \mu \mathrm{L}$ each of the forward and reverse primer $(10 \mathrm{pmol} / \mathrm{uL})$ with the following primer set: CKB-qPCR-F/CKB-qPCR-R: (5'-GACACCCAGTGGATTTACTC-3'/5'-GTCCAGCAGCTCTTTGAAGA), NNVRNA2-qPCR-F/NN VRNA2-qPCR-R: (5'-TGTCGCTGGAGTGTTCG-3'/5'-GAAGTCATTTGTGGAAAGGGAATC-3'). The amplification condition was initial denaturation at $95^{\circ} \mathrm{C}$ for $5 \mathrm{~min}$, followed by 40 cycles of $95^{\circ} \mathrm{C}$ for $5 \mathrm{~s}$, then $65^{\circ} \mathrm{C}$ for $30 \mathrm{~s}$. The melting curve and cooling were performed at the last step of qPCR. The primers used in this study were listed in Table 1 . The expression levels of the target gene were normalized to beta-actin, a housekeeping gene. Fold change in the relative gene expression with control group was determined by the standard $2^{-\Delta \Delta C t}$ method. The changes were analyzed by unpaired sample $t$-test. Statistical significance was accepted at $p<0.05$, and high significance was accepted at $p<0.01$. All data were expressed as mean \pm standard deviation (mean \pm SD). 
Table 1. Mass spectrometry (MS) analysis of groupers optic nerve proteins that can interact with NNVCP by immunoprecipitation (IP).

\begin{tabular}{|c|c|}
\hline \multicolumn{2}{|c|}{ Protein Functional Classification and Description } \\
\hline \begin{tabular}{ll}
\multicolumn{2}{l}{ Ribosomal protein } \\
- & ribosomal protein S7 \\
- & ribosomal protein LP0 \\
- & ribosomal protein $\mathrm{L} 7$ \\
- & ribosomal protein $\mathrm{L} 23$ \\
- & $60 \mathrm{~S}$ ribosomal protein LP1 \\
- & $60 \mathrm{~S}$ ribosomal protein L31
\end{tabular} & $\begin{array}{ll}\text { - } & 60 \mathrm{~S} \text { ribosomal protein } \mathrm{L} 30 \\
\text { - } & \text { ribosomal protein S13 } \\
\text { - } & 60 \mathrm{~S} \text { ribosomal protein } \mathrm{L} 27 \\
\text { - } & 40 \mathrm{~S} \text { ribosomal protein } \mathrm{S} 2 \\
\text { - } & 60 \mathrm{~S} \text { ribosomal protein } \mathrm{L} 13 \\
\text { - } & 40 \mathrm{~S} \text { ribosomal protein } \mathrm{S} 18\end{array}$ \\
\hline $\begin{array}{l}\text { Immunity } \\
\text { - heat shock protein } 60 \\
\text { - } \quad \text { immunoglobulin light chain } \\
\text { - heat shock protein } 90 \\
\text { - } \quad \text { immunoglobulin light chain }\end{array}$ & $\begin{array}{l}\text { - } \quad \text { immunoglobulin mu heavy chain } \\
\text { - } \quad \text { natural killer cell enhancement factor } \\
\text { - } \quad \text { immunoglobulin heavy chain variable region }\end{array}$ \\
\hline $\begin{array}{l}\text { Glucose metabolisms and ATP generation } \\
\text { - } \quad \text { ADP-ATP translocase } \\
\text { - } \quad \text { transferrin } \\
\text { - } \quad \text { nucleoside-diphosphate kinase } \\
\text { - } \quad \text { fructose-bisphosphate aldolase A }\end{array}$ & $\begin{array}{l}\text { - } \quad \text { creatine kinase } \\
\text { - } \quad \text { tryptase-2 precursor } \\
\text { - } \quad \text { triosephosphate isomerase B }\end{array}$ \\
\hline 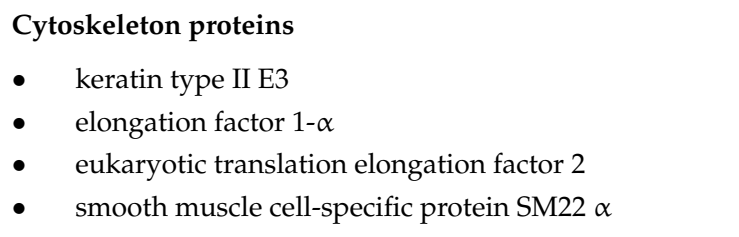 & $\begin{array}{l}\text { - } \quad \text { tropomyosin } \alpha-4 \text { chain } \\
\text { - } \text { myosin light chain } 3 \\
\text { - } \quad \text { tropomyosin }\end{array}$ \\
\hline $\begin{array}{l}\mathrm{Ca}^{2+} \text { binding protein } \\
\text { - } \quad \text { calmodulin } \\
\text { - } \quad \text { ictacalcin } \\
\text { - } \quad \text { galactoside binding lectin }\end{array}$ & $\begin{array}{l}\text { - } \quad \text { S100-like calcium binding protein } \\
\text { - } \quad \text { calreticulin }\end{array}$ \\
\hline $\begin{array}{l}\text { Ion regulation protein } \\
\text { - } \quad \text { voltage-dependent anion selective channel protein } 2 \\
\text { Lipid metabolism proteins }\end{array}$ & - $\quad$ voltage dependent anion channel protein 1 \\
\hline $\begin{array}{ll}\text { - } & \text { apolipoprotein AI } \\
\text { - } & 14 \mathrm{kDa} \text { apolipoprotein }\end{array}$ & - brain-type fatty acid binding protein \\
\hline $\begin{array}{l}\text { Apoptosis protein } \\
\text { - glyceraldehyde-3-phosphate dehydrogenase }\end{array}$ & - $\quad$ ran protein \\
\hline $\begin{array}{l}\text { Protein hydrolysis } \\
\text { - } \quad \text { aldehyde dehydrogenase family } 9\end{array}$ & - $\quad$ lactate dehydrogenase-A \\
\hline $\begin{array}{l}\text { Other } \\
\text { - hemoglobin } \alpha \text { chain }\end{array}$ & - Hnrpa01 protein \\
\hline
\end{tabular}

\section{Results}

3.1. Identification of Optic Nerve Proteins Interacting with Native NNV Capsid Protein (NNVCP) by Proteomic Analysis of Immunoprecipitation (IP) Assay

To identify host proteins interacting with native NNVCP, the protein-protein interaction assay was performed using an IP assay with natural NNVCP and grouper optic nerve tissue. Protein A beads conjugated with anti-NNVCP specific antibody were first incubated with native NNVCP produced from NNV-infected GF-1 cells and then co-incubated with lysates from grouper optic nerve 
tissue (Figure 1, lane 1). In the control group, Protein A beads conjugated with anti-NNVCP specific antibodies were incubated directly with the lysate of the optic nerve tissue without adding native NNVCP (Figure 1, lane 2). Three obvious bands were detected in Figure 1: $37 \mathrm{kDa}$ is native NNVCP (Figure 1, lane 1 and lane 4), $25 \mathrm{kDa}$ is the light chain of anti-NNVCP specific antibody, and $50 \mathrm{kDa}$ is the heavy chain of anti-NNVCP specific antibody (Figure 1, lane1 and lane 2). Lane 3 revealed that grouper optic nerve was non-infected NNV. After IP, samples were preliminary evaluated by SDS-PAGE and Western blot. Through mass spectrometry (MS) analysis of optic nerve IP cleavage samples, it was identified that many grouper proteins could interact with NNVCP, and the proteins were analyzed and annotated (Tables 1 and 2). The score in Table 2 indicates the protein score (MudPI score), which is the sum of the peptide score [26]. MS analysis of the grouper optic nerve protein that can interact with NNVCP found 287 peptides belonging to 49 proteins. Among the proteins involved in multiple functional categories, 12 are ribosomal proteins, 7 are involved in immunity including heat shock protein 60 and heat shock protein 90, 7 are involved in glucose metabolism and ATP generation (such as creatine kinase), 7 are related to the cytoskeleton, 5 are $\mathrm{Ca}^{2+}$ binding proteins, 2 are ion regulation proteins, 3 are involved in lipid metabolism, 2 are involved in apoptosis, and 2 are involved in protein hydrolysis. The functions of hemoglobin $\alpha$ chain and Hnrpa01 protein are not very clear (Table 1).

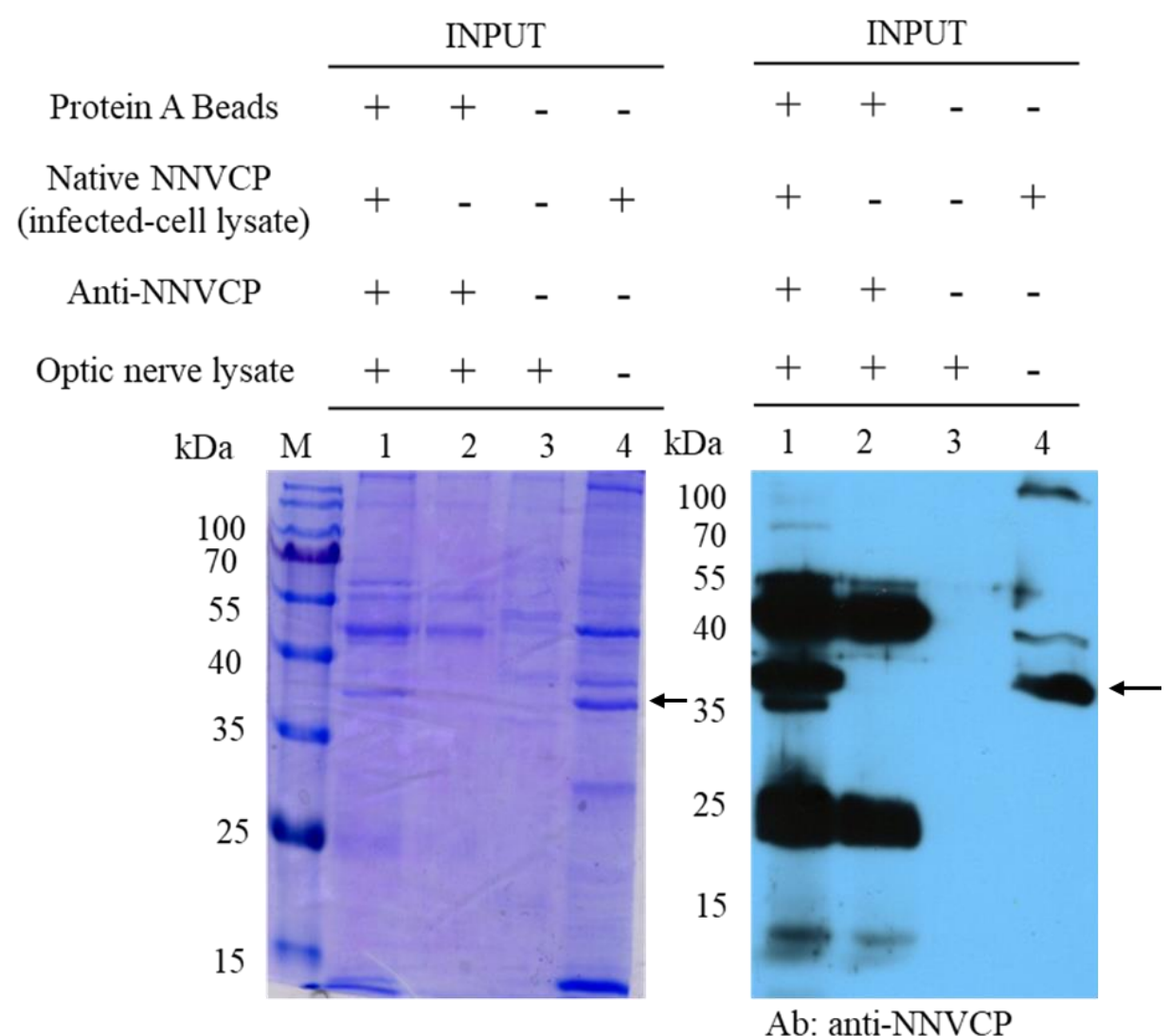

Figure 1. Nervous necrosis virus capsid protein (NNVCP) interactions with grouper optic nerve proteins. SDS-PAGE and Western blot analysis of the grouper proteins that interact with NNVCP by immunoprecipitation (IP) assay. The sample was loaded in every well (listed above the gel) and then detected with the NNVCP antibody. Each well was loaded with $20 \mu \mathrm{g}$ of protein. Lane 1: lysates from grouper optic nerve and native NNVCP were subjected to immunoprecipitation with Protein A beads. Lane 2: lysates from grouper optic nerve were subjected to immunoprecipitation with Protein A beads (negative control). Lane 3: lysates from non-infect grouper optic nerve. Lane 4: Native NNVCP from infected-cell lysate. The arrow indicates native NNVCP. 
Table 2. The original protein assay data in the grouper optic nerve with native NNVCP by immunoprecipitation. The gray font indicates the proteins that were also detected in the control group.

\begin{tabular}{|c|c|c|}
\hline GenBank Accession No. & Description & Score * \\
\hline AAR97600.2 & beta actin (Epinephelus coioides) & 2492.00 \\
\hline 3JBM & C Chain C, Virus-like Particle of Orange-spotted Grouper Nervous Necrosis Virus & 1706.91 \\
\hline AER42656.1 & keratin 8, partial (Epinephelus coioides) & 1457.49 \\
\hline AAX78203.1 & immunoglobulin mu heavy chain (Epinephelus coioides) & 1263.15 \\
\hline AAX78206.1 & immunoglobulin mu heavy chain (Epinephelus coioides) & 999.30 \\
\hline AGG55392.1 & voltage-dependent anion selective channel protein 2 (Epinephelus coioides) & 944.17 \\
\hline AAX78208.1 & immunoglobulin mu heavy chain (Epinephelus coioides) & 914.30 \\
\hline AEG78351.1 & keratin type II E3, partial (Epinephelus coioides) & 790.40 \\
\hline ACM48181.1 & apolipoprotein AI, partial (Epinephelus coioides) & 745.80 \\
\hline AGG55391.1 & heat shock cognate protein 70 (Epinephelus coioides) & 745.79 \\
\hline ACH73075.1 & keratin 8, partial (Epinephelus coioides) & 740.04 \\
\hline AIS72878.1 & heat shock protein 60 (Epinephelus coioides) & 679.74 \\
\hline AEW43726.1 & transferrin (Epinephelus coioides) & 645.54 \\
\hline AER42652.1 & hemoglobin beta chain (Epinephelus coioides) & 623.08 \\
\hline ADG29138.1 & tropomyosin (Epinephelus coioides) & 539.59 \\
\hline ABW74631.1 & immunoglobulin light chain (Epinephelus coioides) & 504.86 \\
\hline AHB51756.1 & calmodulin (Epinephelus coioides) & 491.05 \\
\hline ABW04131.1 & glyceraldehyde-3-phosphate dehydrogenase, partial (Epinephelus coioides) & 484.23 \\
\hline AAS55942.1 & immunoglobulin light chain variable region (Epinephelus coioides) & 476.38 \\
\hline ABW04145.1 & smooth muscle cell-specific protein SM22 alpha (Epinephelus coioides) & 430.16 \\
\hline AEO89322.1 & voltage dependent anion channel protein 1 (Epinephelus coioides) & 421.60 \\
\hline AER42688.1 & tropomyosin alpha-4 chain, partial (Epinephelus coioides) & 418.42 \\
\hline ABW04135.1 & natural killer cell enhancement factor (Epinephelus coioides) & 361.05 \\
\hline AEG78406.1 & hemoglobin alpha chain, partial (Epinephelus coioides) & 347.41 \\
\hline ADG29126.1 & fructose-bisphosphate aldolase A (Epinephelus coioides) & 340.73 \\
\hline AEG78409.1 & $60 S$ ribosomal protein L30 (Epinephelus coioides) & 325.27 \\
\hline ADG29180.1 & triosephosphate isomerase B (Epinephelus coioides) & 310.40 \\
\hline ACL98136.1 & type I keratin, partial (Epinephelus coioides) & 305.82 \\
\hline ABW04143.1 & S100-like calcium binding protein (Epinephelus coioides) & 298.82 \\
\hline ABW04124.1 & ADP-ATP translocase (Epinephelus coioides) & 288.91 \\
\hline ACH73065.1 & ribosomal protein S7 (Epinephelus coioides) & 283.43 \\
\hline ADZ76534.1 & myosin light chain 3 (Epinephelus coioides) & 279.24 \\
\hline ABW04132.1 & Hnrpa01 protein, partial (Epinephelus coioides) & 269.70 \\
\hline ACV04938.1 & heat shock protein 90 (Epinephelus coioides) & 269.27 \\
\hline ADG29156.1 & histone H2B (Epinephelus coioides) & 265.26 \\
\hline AOW69105.1 & elongation factor 1-alpha (Epinephelus coioides) & 264.68 \\
\hline ADG29136.1 & beta-enolase (Epinephelus coioides) & 247.11 \\
\hline AEG78428.1 & $60 \mathrm{~S}$ ribosomal protein L10a (Epinephelus coioides) & 246.47 \\
\hline AAW29021.1 & lactate dehydrogenase-A, partial (Epinephelus coioides) & 212.87 \\
\hline ABW04139.1 & ribosomal protein LP0 (Epinephelus coioides) & 212.25 \\
\hline ABW04136.1 & nucleoside-diphosphate kinase (Epinephelus coioides) & 199.15 \\
\hline ADG29150.1 & 60S ribosomal protein L19, partial (Epinephelus coioides) & 186.15 \\
\hline ADG29176.1 & muscle phosphoglycerate mutase 2 (Epinephelus coioides) & 184.01 \\
\hline ACH73061.1 & ribosomal protein L7, partial (Epinephelus coioides) & 157.36 \\
\hline ABW04127.1 & brain-type fatty acid binding protein (Epinephelus coioides) & 156.32 \\
\hline ABW04123.1 & $60 S$ ribosomal protein L27 (Epinephelus coioides) & 152.44 \\
\hline ADZ99127.1 & immunoglobulin heavy chain variable region, partial (Epinephelus coioides) & 146.61 \\
\hline
\end{tabular}


Table 2. Cont.

\begin{tabular}{ccc}
\hline GenBank Accession No. & Description & Score $^{*}$ \\
\hline AEG78395.1 & aldehyde dehydrogenase family 9 member A1-A, partial (Epinephelus coioides) & 136.08 \\
\hline ADG29178.1 & tryptase-2 precursor, partial (Epinephelus coioides) & 135.49 \\
\hline ACL98142.1 & desmin, partial (Epinephelus coioides) & 120.60 \\
\hline ABW04138.1 & ribosomal protein L23, partial (Epinephelus coioides) & 110.93 \\
\hline ACH73060.1 & ictacalcin (Epinephelus coioides) & 104.23 \\
\hline ABW04130.1 & galactoside binding lectin (Epinephelus coioides) & 100.05 \\
\hline AER42692.1 & 60S ribosomal protein LP1 (Epinephelus coioides) & 99.41 \\
\hline AEG78402.1 & 40S ribosomal protein S18 (Epinephelus coioides) & 87.32 \\
\hline ADG29169.1 & 60S ribosomal protein L13, partial (Epinephelus coioides) & 86.49 \\
\hline ADG29143.1 & 60S ribosomal protein L31 (Epinephelus coioides) & 67.76 \\
\hline ACM41841.1 & creatine kinase, partial (Epinephelus coioides) & 58.09 \\
\hline AEG78365.1 & 40S ribosomal protein S2 (Epinephelus coioides) & 57.41 \\
\hline AEG78426.1 & immunoglobulin light chain (Epinephelus coioides) & 55.83 \\
\hline ABW74647.1 & 14 kDa apolipoprotein, partial (Epinephelus coioides) & 51.54 \\
\hline ACM41842.1 & ran protein, partial (Epinephelus coioides) & 50.87 \\
\hline ACL98134.1 & calreticulin (Epinephelus coioides) & 48.98 \\
\hline AHA43788.1 & *ukaryotic translation elongation factor 2, partial (Epinephelus coioides) & 38.35 \\
\hline ABW04141.1 & ribosomal protein S13, partial (Epinephelus coioides) & 32.62 \\
\hline
\end{tabular}

\subsection{Sequence Analysis of Grouper Creatine Kinase (CK) Protein and Phylogenetic Construction}

According to the EST database, an unpublished sequence with an opening reading frame (ORF) was identified. This ORF encodes a protein of 361 amino acids with a theoretical size of about $42 \mathrm{kDa}$. The nucleotide sequence surrounding the methionine start codon (GCCATG) of the predicted protein conformed to the Kozak rule of an efficient context for eukaryotic translation initiation. A polyadenylation signal (AAGTAA) was located $1147 \mathrm{bp}$ downstream of the translational stop codon. The deduced amino acid sequence of the ORF was homologous with known grouper CK protein (Figure 2A). A phylogenetic tree was constructed by analyzing the amino acid sequence of grouper CK and the $12 \mathrm{CK}$ protein. The results indicated that grouper CK protein identified to a high degree with those of similar genes in six fish species CK brain type (CKB) compared with CK muscle type (CK M) (Figure 2B). 
1 ATGCCTTTCGGTAACACACACAACCAGATGAAGATGAAGTACTCCTCGGAGCAGGAGTACCCGGACCTCAGCAAA

$\begin{array}{lllllllllllllllllllllllllll}1 & \text { M } & \text { P } & \text { F } & \text { G } & \text { N } & \text { T } & \text { H } & \text { N } & \text { Q } & \text { M } & \text { K } & \text { M } & \text { K } & \text { Y } & \text { S } & \text { S } & \text { E } & \text { Q } & \text { E } & \text { Y } & \text { P } & \text { D } & \text { L } & \text { S } & \text { K }\end{array}$

76 CACAACAATCATATGGCCAAGGTCCTGACTGCTGCTATGTACGAGCGGCTGAGGAGCAAACAGACACCCAGTGGA

$\begin{array}{lllllllllllllllllllllllllll}26 & \text { H } & \text { N } & \text { N } & \text { H } & \text { M } & \text { A } & \text { K } & \text { V } & \text { L } & \text { T } & \text { A } & \text { A } & \text { M } & \text { Y } & \text { E } & \text { R } & \text { L } & \text { R } & \text { S } & \text { K } & \text { Q } & \text { T } & \text { P } & \text { S } & \text { G }\end{array}$

151 TTTACTCTGGATGATGTCATTCAGACTGGGGTTGACAACCCAGGCCACCCCTTCATCATGACCGTGGGCTGCGTC

$\begin{array}{lllllllllllllllllllllllllll}51 & \text { F } & \text { T } & \text { L } & \text { D } & \text { D } & \text { V } & \text { I } & \mathcal{Q} & \text { T } & \text { G } & \text { V } & \text { D } & \text { N } & \text { P } & \text { G } & \text { H } & \text { P } & \text { F } & \text { I } & \text { M } & \text { T } & \text { V } & \text { G } & \text { C } & \text { V }\end{array}$

226 GCCGGAGACGAGGAGTCCTATGAGGTCTTCAAAGAGCTGCTGGACCCCGTGATCGAGGACCGTCATGGAGGATAC

$\begin{array}{lllllllllllllllllllllllllll}76 & \text { A } & \text { G } & \text { D } & \text { E } & \text { E } & \text { S } & \text { Y } & \text { E } & \text { V } & \text { F } & \text { K } & \text { E } & \text { L } & \text { L } & \text { D } & \text { P } & \text { V } & \text { I } & \text { E } & \text { D } & \text { R } & \text { H } & \text { G } & \text { G } & \text { Y }\end{array}$

301 AAACCCACAGACAAGCACAAGACCGACCTCAACTCAGCCAACCTGAAGGGAGGTGATGACCTCGACCCCAACTAC $\begin{array}{lllllllllllllllllllllllllll}101 & \text { K } & \text { P } & \text { T } & \text { D } & \text { K } & \text { H } & \text { K } & \text { T } & \text { D } & \text { L } & \text { N } & \text { S } & \text { A } & \text { N } & \text { L } & \text { K } & \text { G } & \text { G } & \text { D } & \text { D } & \text { L } & \text { D } & \text { P } & \text { N } & \text { Y }\end{array}$ 376 GTCCTGAGCTCCCGAGTCCGCACAGGCCGCAGCGTCCGTGGCTTCTGCCTGCCACCTCACTGCAGCCGAGGAGAG $\begin{array}{lllllllllllllllllllllllllll}126 & \mathrm{~V} & \mathrm{~L} & \mathrm{~S} & \mathrm{~S} & \mathrm{R} & \mathrm{V} & \mathrm{R} & \mathrm{T} & \mathrm{G} & \mathrm{R} & \mathrm{S} & \mathrm{V} & \mathrm{R} & \mathrm{G} & \mathrm{F} & \mathrm{C} & \mathrm{L} & \mathrm{P} & \mathrm{P} & \mathrm{H} & \mathrm{C} & \mathrm{S} & \mathrm{R} & \mathrm{G} & \mathrm{E}\end{array}$ 451 AGGCGTGCTGTGGAGAAGCTCTCCATCGAAGCTCTGGCCGCCCTGAGCGGAGACCTGAAGGGGAAGTACTACGCC $\begin{array}{llllllllllllllllllllllllll}151 & \text { R } & \text { R } & \text { A } & \text { V } & \text { E } & \text { K } & \text { L } & \text { S } & \text { I } & \text { E } & \text { A } & \text { L } & \text { A } & \text { A } & \text { L } & \text { S } & \text { G } & \text { D } & \text { L } & \text { K } & \text { G } & \text { K } & \text { Y } & \text { Y } & \text { A }\end{array}$ 526 CTGAAGAACATGACGGAGGCTGAGCAGCAGCAGCTCATCGATGACCACTTCCTGTTTGACAAGCCAGTGTCTCCT $\begin{array}{lllllllllllllllllllllllllll}176 & \text { L } & \text { K } & \text { N } & \text { M } & \text { T } & \text { E } & \text { A } & \text { E } & \text { Q } & \text { Q } & \text { Q } & \text { L } & \text { I } & \text { D } & \text { D } & \text { H } & \text { F } & \text { L } & \text { F } & \text { D } & \text { K } & \text { P } & \text { V } & \text { S } & \text { P }\end{array}$ 601 CTGCTGCTGGCCTCAGGGATGGGCCGTGACTGGCCCGACGCCAGGGGCATCTGGCACAATGACAACAAGACATTC $\begin{array}{lllllllllllllllllllllllllll}201 & \text { L } & \text { L } & \text { L } & \text { A } & \text { S } & \text { G } & \text { M } & \text { G } & \text { R } & \text { D } & \text { W } & \text { P } & \text { D } & \text { A } & \text { R } & \text { G } & \text { I } & \text { W } & \text { H } & \text { N } & \text { D } & \text { N } & \text { K } & \text { T } & \text { F }\end{array}$ 676 CTCGTGTGGGTGAATGAGGAGGATCACCTGCGTGTGATCTCTATGCAGAAAGGCGGCAACATGAGGGAAGTCTTC $\begin{array}{lllllllllllllllllllllllllll}226 & \text { L } & \text { V } & \text { W } & \text { V } & \text { N } & \text { E } & \text { E } & \text { D } & \text { H } & \text { L } & \text { R } & \text { V } & \text { I } & \text { S } & \text { M } & \text { Q } & \text { K } & \text { G } & \text { G } & \text { N } & \text { M } & \text { R } & \text { E } & \text { V } & \text { F }\end{array}$ 751 ACTCGCTGGAACGAGCACCTGGGCTACGTCCTCACCTGCCCATCTAACCTGGGCACCGGCCTGCGTGCTGGTGTT $\begin{array}{lllllllllllllllllllllllllll}251 & \text { T } & \text { R } & \text { W } & \text { N } & \text { E } & \text { H } & \text { L } & \text { G } & \text { Y } & \text { V } & \text { L } & \text { T } & \text { C } & \text { P } & \text { S } & \text { N } & \text { L } & \text { G } & \text { T } & \text { G } & \text { L } & \text { R } & \text { A } & \text { G } & \text { V }\end{array}$ 826 CACGTCAAACTGCCCAACATGAGCAAACACGCCAAGTTTGAGGAGGTTCTCAAGAAGCTGAGGCTCCAGAAACGT $\begin{array}{llllllllllllllllllllllllll}276 & \text { H } & \text { V } & \text { K } & \text { L } & \text { P } & \text { N } & \text { M } & \text { S } & \text { K } & \text { H } & \text { A } & \text { K } & \text { F } & \text { E } & \text { E } & \text { V } & \text { L } & \text { K } & \text { K } & \text { L } & R & \text { L } & Q & \text { K } & R\end{array}$ 901 GGAACTGGTGGAGTGGACACAGCCGCTGTGGGTGGAGTGTTTGACATCTCCAACGCCGACAGACTGGGCTTCTCT $\begin{array}{lllllllllllllllllllllllllll}301 & G & \text { T } & \text { G } & \text { G } & \text { V } & \text { D } & \text { T } & \text { A } & \text { A } & \text { V } & \text { G } & \text { G } & \text { V } & \text { F } & \text { D } & \text { I } & \text { S } & \text { N } & \text { A } & \text { D } & \text { R } & \text { L } & \text { G } & \text { F } & \text { S }\end{array}$ 976 GAGGTGGAGCTGGTGCAGATGGTGGTTGATGGCGTCAAGCTGCTGGTGGACATGGAGAAGAGGCTGGAGAAGGGC $\begin{array}{llllllllllllllllllllllllllll}326 & E & \text { V } & \text { E } & \text { L } & \text { V } & \text { Q } & \text { M } & \text { V } & \text { V } & \text { D } & \text { G } & \text { V } & \text { K } & \text { L } & \text { L } & \text { V } & \text { D } & \text { M } & \text { E } & \text { K } & \text { R } & \text { L } & \text { E } & K & G\end{array}$ 1051 CAgtCCATCGACGACCTCATGCCCGCCCAGAAGTAA

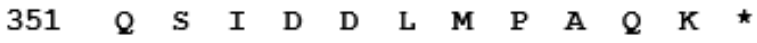

(A) Creatine kinase protein amino acid sequence analyses.

Figure 2. Cont. 


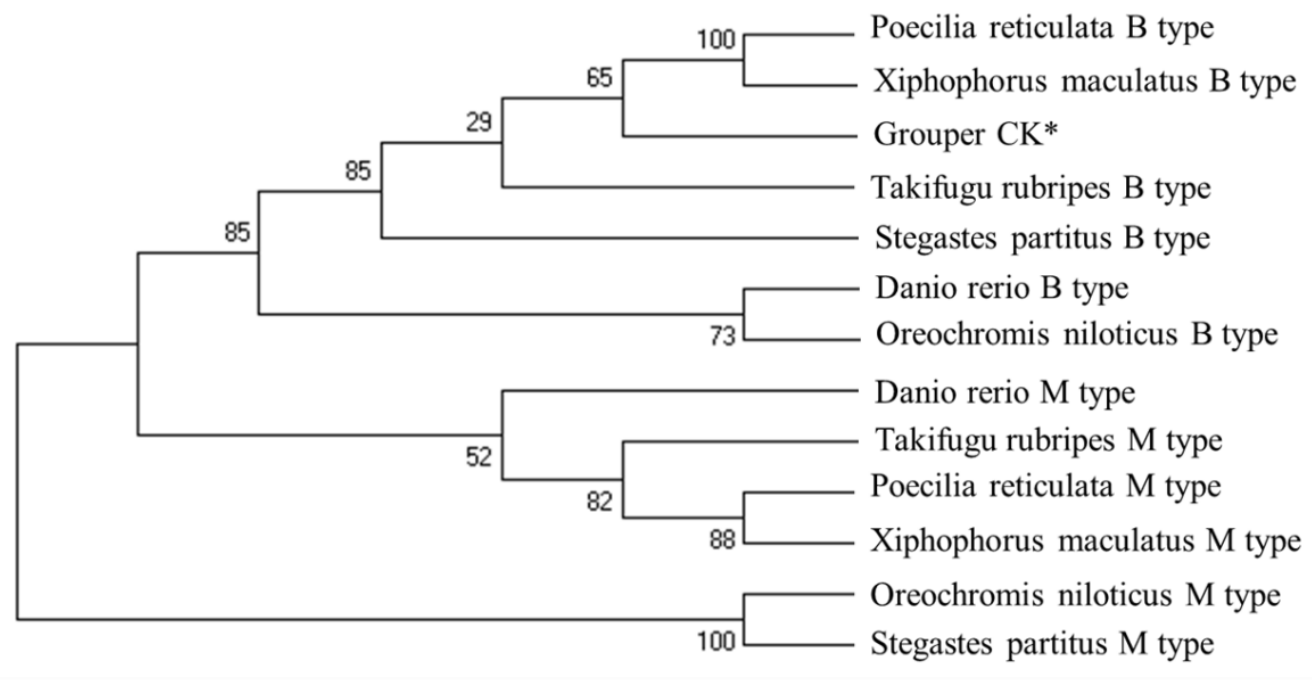

0.2

(B) Phylogenetic construction.

Figure 2. The sequence and phylogenetic analysis of grouper CK. The sequence and phylogenetic analysis of grouper CK. (A) the nucleotide sequence and deduced amino acid sequence. (B) The phylogenetic tree was constructed by the neighbor-joining method and shows relatedness of 12 CK fish organisms. Robustness was tested by 1000 bootstrap replications and the indicated distance given the value of 0.1 means the $10 \%$ differences in amino acid residues between compared sequences. Bootstrap values are given in percentages. * represents the grouper CK sequence used in this study.

\subsection{CKB Interacted with NNVCP In Vitro}

To confirm the interaction of CKB with NNVCP, far-Western blot assay was applied to check the protein-protein interaction in vitro. Recombinant CKB ( $\mathrm{rCKB}$ ) and NNVCP (rNNVCP) were generated by the Escherichia coli expression system, and shrimp maltose binding protein (rMBP) was used as a negative control [27]. The Western blot revealed that $\mathrm{rCKB}$ protein could be specifically recognized by anti-Ckba antibody (Figure 3B, lane 1 and 2, $42 \mathrm{kDa}$ ). However, rMBP could not be recognized by anti-Ckba antibody (Figure 3B, lane 3, $38 \mathrm{kDa}$ ) In the far-Western blot analysis, after hybridizing with $\mathrm{rCKB}$ and reacting with anti-Ckba antiserum, $\mathrm{rCKB}$ showed that it could interact with $\mathrm{rNNVCP}$ (Figure 3D, lane 1). As a negative control, rMBP could not interact with rCKB (Figure 3D, lane 2). The results indicated that $\mathrm{CKB}$ can interact with NNVCP. 
A

B

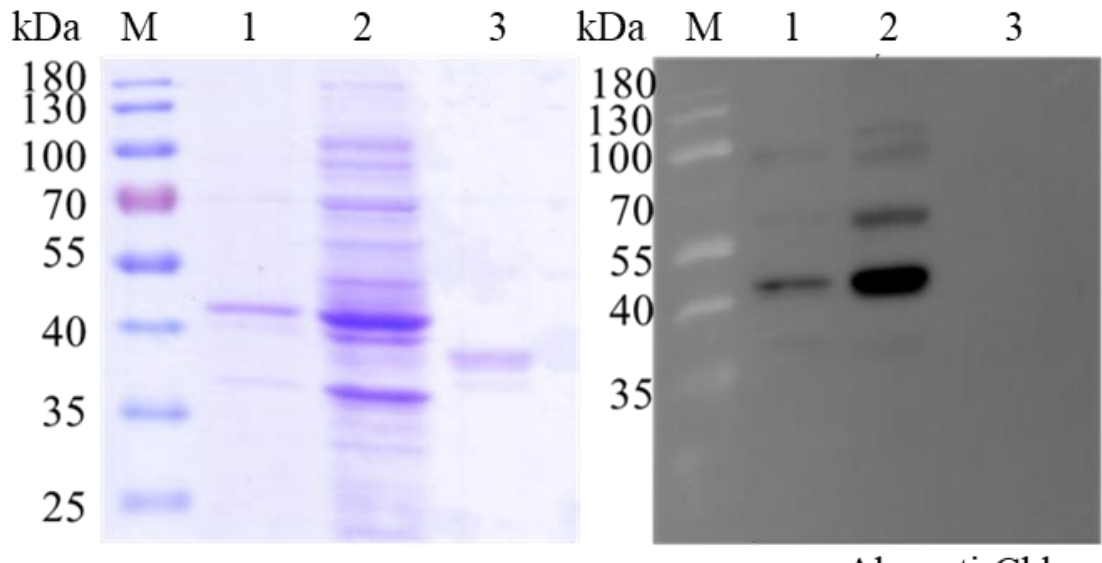

Ab: anti-Ckba

C

$\mathrm{D}$

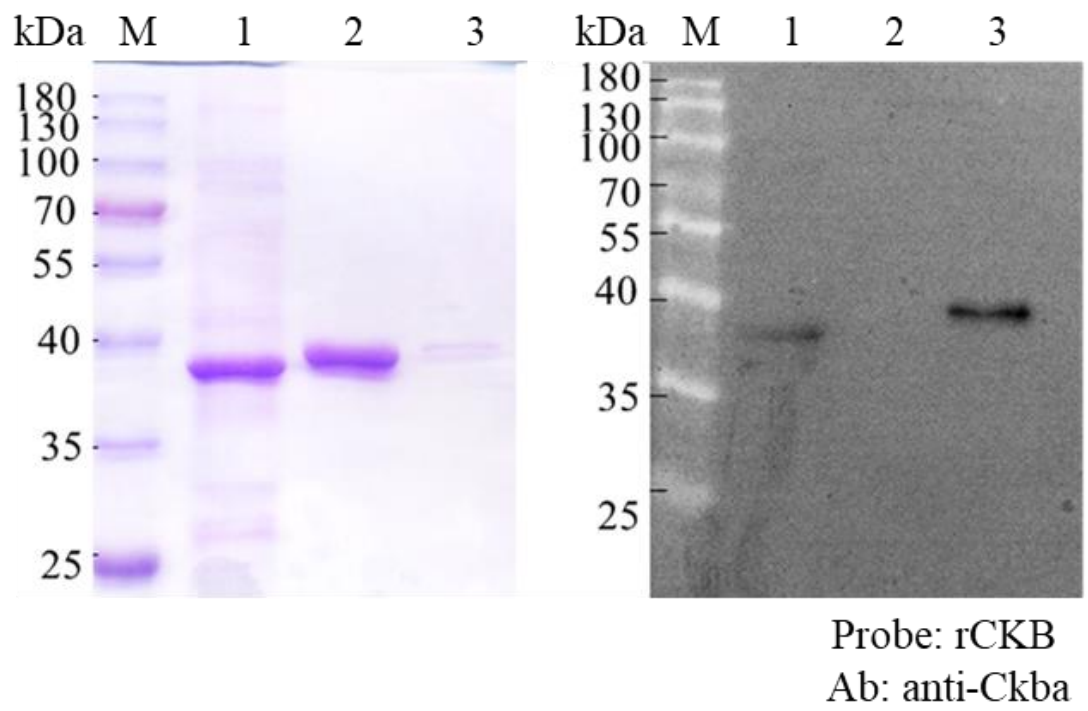

Figure 3. $\mathrm{rCKB}$ interacts with $\mathrm{rNNVCP}$ in vitro. $\mathrm{rCKB}$ interacts with $\mathrm{rNNVCP}$ in vitro. (A) SDS-PAGE and $(B)$ Western blotting were used to determine the recombinant CK B-type (rCKB) generated by Escherichia coli. Lane M: pre-stained molecular weight marker. Lane 1: purified rCKB. Lane 2: rCKB in E. coli whole lysate. Lane 3: purified rMBP. rCKB protein can be specifically recognized by anti-Ckba antibody. (C) SDS-PAGE and (D) far-Western blotting were used to determine the interaction between rCKB and rNNVCP. Lane M: marker. Lane 1: rNNVCP. Lane 2: rMBP. Lane 3: rCKB. PVDF membrane was first incubated with $\mathrm{rCKB}$ (probe) and then reacted with anti-Ckba antibody. Each well was loaded with $20 \mu \mathrm{g}$ of protein. rMBP was treated as negative control.

\subsection{CKB Colocalized with NNVCP in the GF-1 Cell Line}

The interaction of CKB and NNVCP was further validated in vivo by the GF-1 cell line. Since GF-1 cells do not express CKB, this experiment was carried out by transfecting the cells with CKB-pcDNA3 plasmid and then infecting them with NNV. In previous studies, it was found that CKB is distributed throughout the cell, but mainly in the perinuclear area [28]. 48 hours after transfection, the same phenomena were observed in GF-1 cells. CKB proteins were observed in the perinuclear area of GF-1 cells transfected with pcDNA3-CKB (Figure 4A, red fluorescent signals). However, no immunofluorescent signal was detected in GF-1 cells transfected with pcDNA3 only (Figure 4C). Two days after transfection, the cells were infected with NNV. After infection with NNV for $24 \mathrm{~h}$, NNVCP signal was predominantly detected at the nucleus of GF-1 cells (Figure 4B,C, green fluorescent 
signals). As shown in Figure 4, the immunofluorescent signal of CKB was enhanced after NNV infected the GF-1 cells transfected with pcDNA3-CKB. Furthermore, CKB colocalized with NNVCP in the perinuclear area of NNV-infected GF-1 cells (Figure 4B, Merge).

pcDNA3-CKB
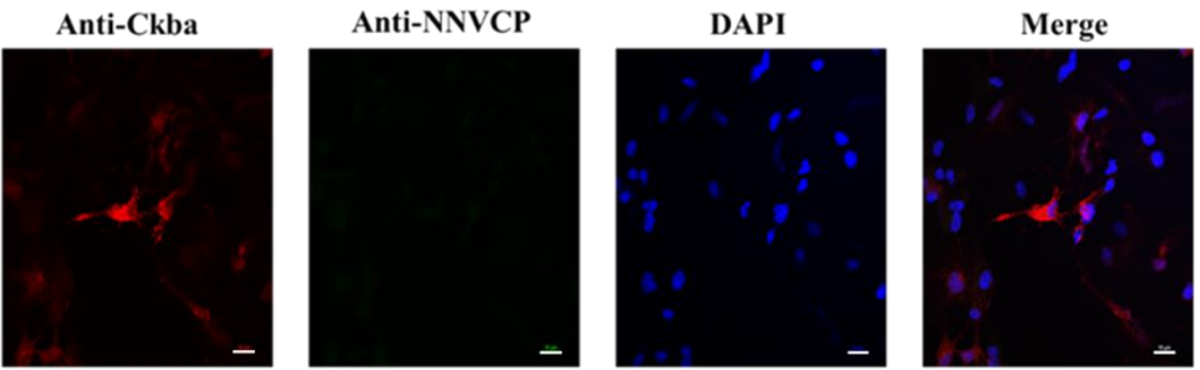

(B)

pcDNA3-CKB

$+$

NNV
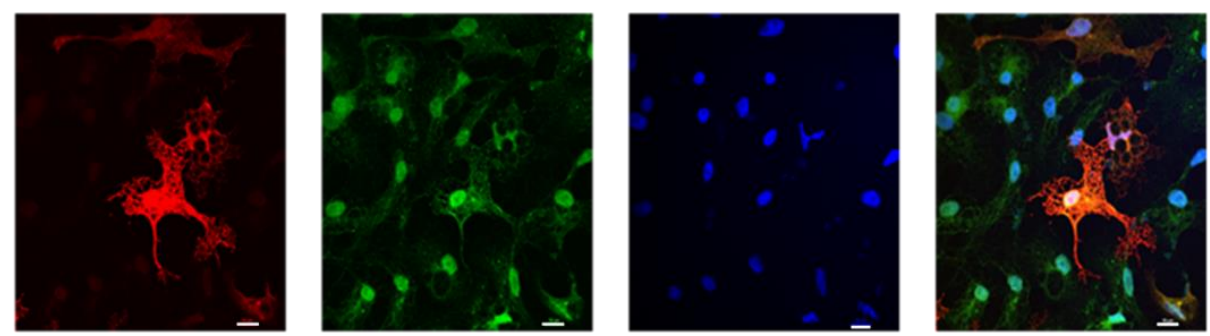

(C)
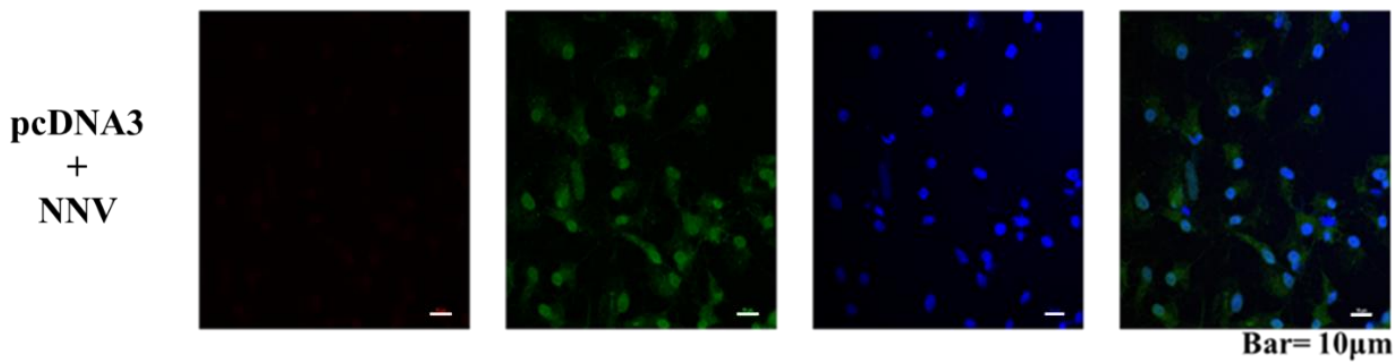

Figure 4. The colocalization between CKB and NNVCP in the GF-1 cell by confocal microscopy. The colocalization between $\mathrm{CKB}$ and NNVCP in the GF-1 cell by confocal microscopy. The red fluorescence represents $\mathrm{CKB}$, the green fluorescence represents NNVCP, and the blue fluorescence DAPI represents the nucleus. Colocalization of CKB and NNVCP is indicated in yellow in this merged. (A) GF-1 cell transfected with pcDNA3-CKB. (B) GF-1 cell transfected with pcDNA3-CKB and infected NNV. (C) GF-1 cell transfected with pcDNA3 and infected NNV. Bar $=10 \mu \mathrm{m}$.

\subsection{CKB Participates in NNV Morphogenesis}

To verify whether CKB is involved in NNV morphogenesis, we compared eye and brain tissues that were not infected with NNV and infected with NNV. The result showed that CKB expression was significantly upregulated in infected tissues compared to the non-infected tissues. The gene expression of CKB upregulates approximately twofold after NNV infection (Figure 5). To further verify whether CKB does contribute to virus replication, the amounts of NNV virus in GF-1 cells transfected with and without CKB were compared. The results showed that the amount of virus in GF-1 cells transfected with pcDNA3-CKB was significantly higher than that in cells transfected with pcDNA3 only (Figure 6). The mRNA expression level of NNVCP in the pcDNA3-CKB group was 5.29 times higher than that in the control group (pcDNA3 only). Based on the above experiments, the results show that CKB does help NNV morphogenesis. 


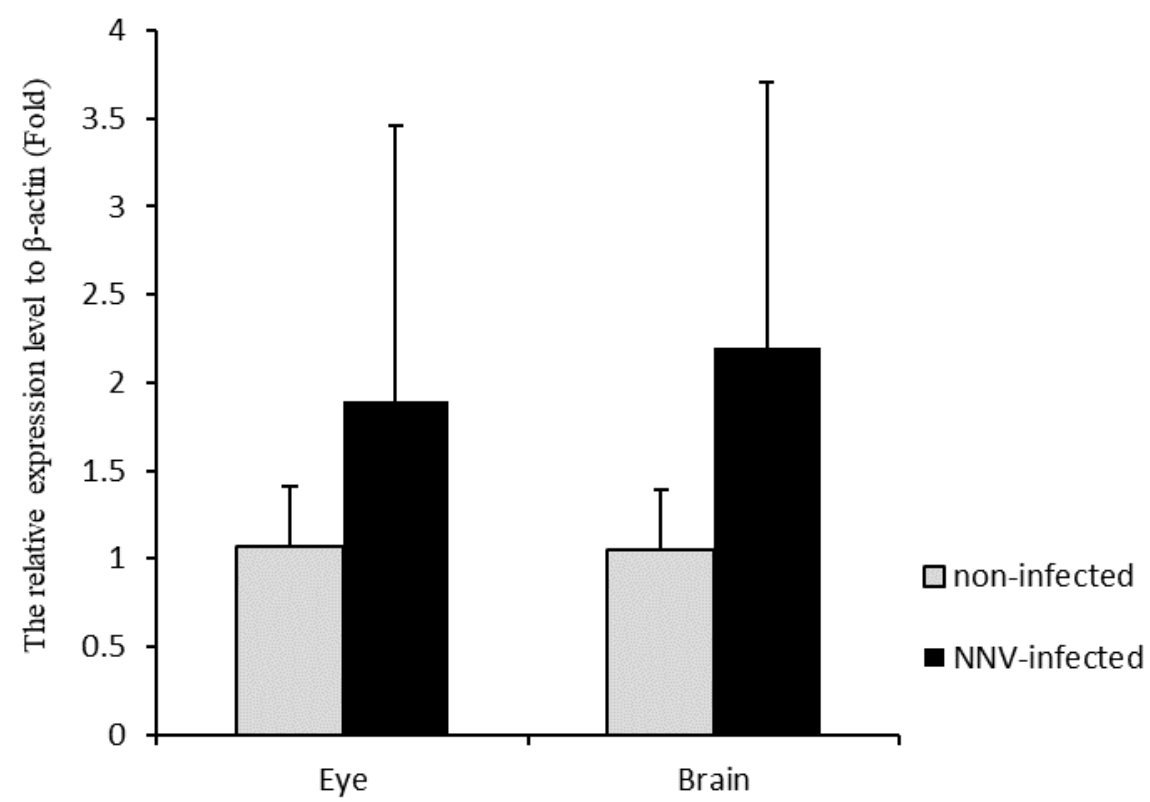

Figure 5. Quantitative real-time PCR analysis of $C K B$ gene expression levels between NNV-infected and non-infected tissues. Quantitative real-time PCR analysis of CKB gene expression levels between NNV-infected tissue and non-infected tissue. The relative expression of CKB was normalized to $\beta$-actin. Vertical bars represent the mean \pm S.D. $(n=4)$.

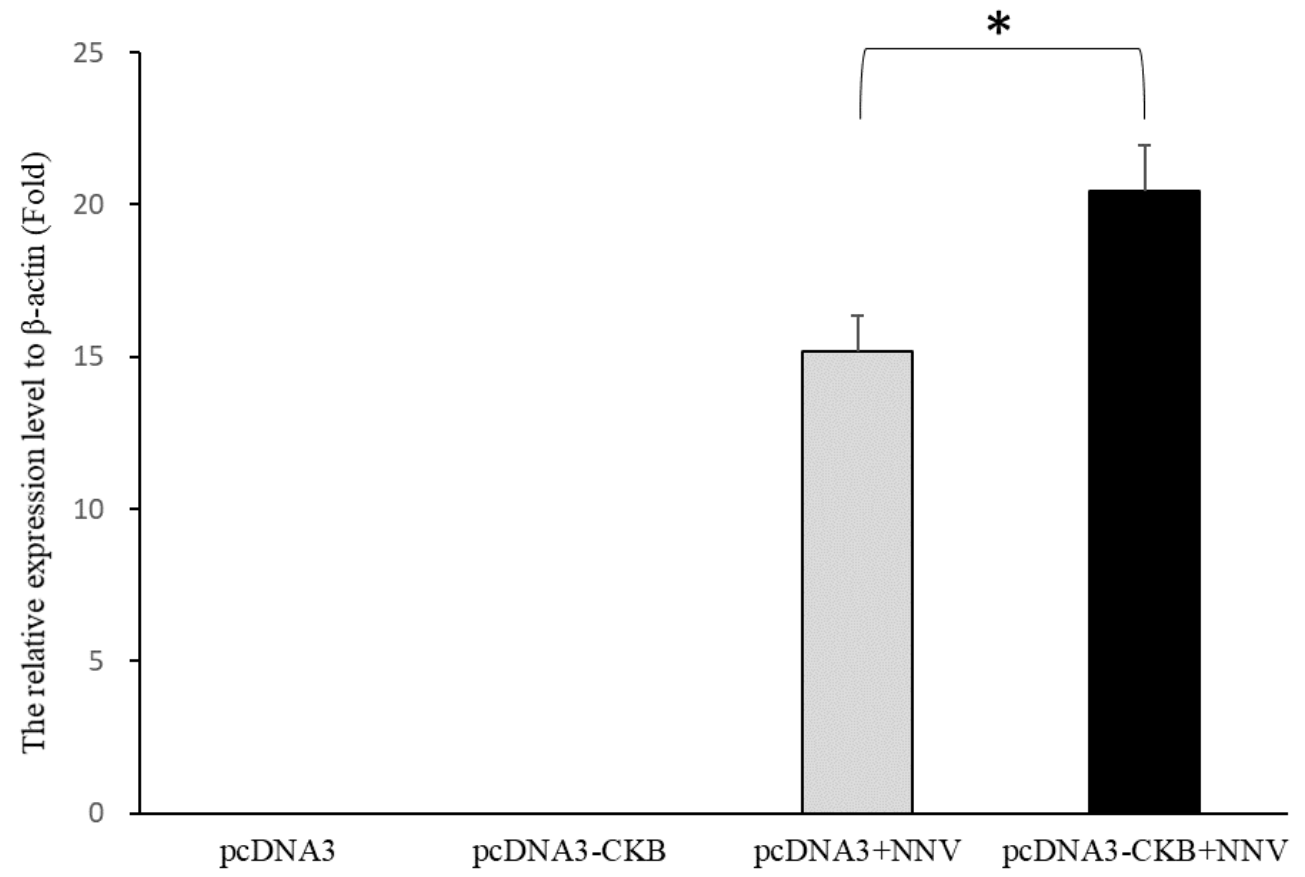

Figure 6. The expression levels of NNVCP gene levels in GF-1 cells after NNV infection. The expression levels of NNVCP gene were measured by quantitative real-time PCR. The relative expression of the NNVCP gene was normalized to $\beta$-actin. Significance was measured using the Student's $t$-test. The data are expressed as the mean \pm S.D. $(n=4)$. An asterisk $(*)$ indicates a significant difference between the experimental and control group. ${ }^{*} p<0.05$.

\section{Discussion}

Nervous necrosis virus (NNV) infection causes high mortality in various economically important fish species worldwide. In recent years, many studies on NNV have been reported, but its infection mechanism remains unclear. In order to accomplish virus morphogenesis, the viral structural protein 
needs to complete a series of common tasks. Those tasks include recognition and binding to host receptors and co-receptors, entry into the cell by endocytosis or membrane fusion, disassembly of the viral capsid structure, and release of the viral genome. Then, newly viral proteins begin packaging the viral genome and assembling into capsid structures, and finally, mature virions exit the host cell. As the only structural protein, NNV capsid protein (NNVCP) should responsibly serve multiple functions in NNV morphogenesis. In this study, immunoprecipitation (IP) was used to analyze the proteins that bind to NNVCP in optic nerve tissues of grouper (Epinephelus coioides) and 49 proteins were identified (Table 1). Several host proteins in our database have been previously confirmed to interact with NNVCP, such as heat shock protein 90 [24] and voltage-dependent anion selective channel protein 2 (VDAC2) that are regarded as required in NNV infection [25]. After comparing the control group, several proteins were excluded from the table, such as histone and HSC70 (Table 2, gray font) [23,29]. Therefore, some proteins that can really bind to NNVCP may be considered as non-specific binding proteins and be eliminated during the screening process. Furthermore, many previous studies found that interferon can inhibit NNV infection [30-33]. However, no interferon was identified in this study; this may be related to the experimental mechanism in which the grouper itself does not have an immune mechanism that produces interferon.

The first step for viruses to complete their life cycle is to bind to host cells, which is determined by the structure of the virus itself and the surface composition of host cells. In 49 optic nerve proteins, the possible candidate receptor may be heat shock protein (HSP). HSC70 and HSP90 have been known as a functional part of the NNV receptor complex, and knockdown HSC70 or HSP90 gene expression could reduce the NNV entry [23,24]. Furthermore, many functions of heat shock proteins were described in different kinds of viruses, such as the entry of rotavirus [34], uncoating of adenovirus [35], viral gene transcription of human immunodeficiency virus type 1 (HIV-1) [36], viral genome replication of hepatitis B virus (HBV) [37-39], and viral capsid assembly of polyomavirus [40]. Three HSPs (HSP60, HSC70, and HSP90) were screened in this study. Apolipoproteins were also found in our results. Apolipoproteins play an important role in hepatitis $\mathrm{C}$ virus $(\mathrm{HCV})$ pathogenesis, including in viral attachment, entry, and assembly [41]. They may not only participate in NNV entry, but also involve other NNV morphogenesis stages.

As the only structural protein of NNV, NNVCP not only participates in the virus entry stage, but also participates in other stages of morphogenesis. Several proteins that were abnormal in dementia or neurological disorders, such as cytoskeleton and nerve proteins, were found to interact with NNVCP. The eukaryotic cytoskeleton is composed of actin microfilaments, microtubules, and intermediate filaments (IFs), which control cell shape, locomotion, intracellular organization, and transport [42]. Keratins are expressed in most epithelial cells, but keratin 8 (KRT8) and keratin 18 (KRT18) are only expressed in hepatocytes [43]. KRT8 is involved in the replication of HBV DNA and was found to enhance HBV replication [44]. In some neurodegenerative diseases such as Alexander's disease and Alzheimer's disease, keratin and desmin aggregates and inclusions can be observed [45,46], and dysregulated keratin expression was observed in Alzheimer's disease [47]. Alexander's disease is an early-onset childhood pathology with clinical symptoms including sudden paralysis, convulsions, and stunting that eventually lead to death, with glial fibrillary acidic protein (GFAP), HSP, and $\alpha$ B-crystallin forming aggregates and inclusion bodies in the astrocyte cytoplasm. Ran and Ran-binding proteins are involved in many diseases. Ran-binding protein 2 mutation will cause a familial form of acute necrotizing encephalopathy, a neurological disorder [48], and Ran-binding protein 9 will have large accumulation in the brains of patients with Alzheimer disease; it is thought to be the generation of the toxic neuropeptide amyloid beta and enhance mitochondrial-mediated apoptosis [49,50]. Aldehyde dehydrogenase protein (ALDH) expression level was decreased in the substantia of Parkinson's disease patients and Alzheimer's disease [51]. Classical swine fever virus (CSFV) inhibits INF expression by binding to hemoglobin and also inhibits INF inhibition when hemoglobin is overexpressed [52]. In HIV patients, low hemoglobin levels were associated with higher interferon and lower transferrin, which may cause anemia in these patients [53]. NNVCP binding to hemoglobin and transferrin may cause 
anemia upon grouper infection with NNV. Collectively, those related proteins were also confirmed to bind to NNVCP in IP database. This result may explain the abnormal behavior, vacuolation, and neuronal degeneration of the brain and retina and anemia in groupers infected with NNV [54], and may be related to necrosis of the central nervous system.

Some calcium-binding proteins were found to interact with NNVCP in the optic nerve tissues, such as calmodulin, ictacalcin, calreticulin, galactoside binding lectin, and S100-A11 calcium-binding protein. Calcium ions $\left(\mathrm{Ca}^{2+}\right)$ play important roles in cell signaling, especially in the endoplasmic reticulum. In Dengue virus-infected cells, the unfolded protein response was associated with $\mathrm{Ca}^{2+}$ signaling [55]. The NNV motif ${ }_{130} \mathrm{DxxDxD}_{135}$ is associated with calcium ions and was found to be crucial for the assembly and stability of NNV particles [56]. Calmodulin (CaM) is a universal intracellular $\mathrm{Ca}^{2+}$ receptor that binds to numerous target proteins and modulates their activities in response to $\mathrm{Ca}^{2+}$ signals. CaM plays a critical regulatory role in essential biological functions such as metabolism, motility, memory, immune responses, and apoptosis [57,58]. Autophagy is important for the replication of numerous DNA and RNA viruses [59]. Autophagy can be initiated by virus-encoded proteins that release ER calcium into the cytoplasm and activate a CaM signaling pathway, after which the virus uses the autophagy membrane trafficking pathway to transport viral proteins for virus replication; for example, CaM interacts with viral proteins involved in HIV-1 replication [60]. The Enterovirus 71 (EV71) VP1 protein can activate CaMKII and has a structural role in viral replication [61]. The IP results in the present study may indicate that calcium-binding related proteins are involved in NNV replication.

Tropomyosin, myosin, and actin were all identified in this study. Several viruses including murine leukemia virus (MLV) and avian leukosis virus (ALV) have been demonstrated to interact with actin and myosin at the cell entry site, which helps these viruses more efficiently infect the host cell [62]. Blocking the myosin-actin interaction could inhibit HIV virus budding [63]. In addition, the actin-myosin network is important and necessary for influenza virus production. In shrimp virus research, the interaction of tropomyosin and white spot syndrome virus VP466 protein (WSSV-VP466) was found to enhance WSSV infection [64]. Tropomyosin, myosin, and actin were all identified in this study, suggesting that NNV may also use these proteins to help virus invasion of host cells, transport within the cells, or virus budding. Additional experiments are needed to investigate this hypothesis.

Virus replication requires energy and macromolecule synthesis, and host cells provide the viruses with metabolic resources necessary for their efficient replication. Thus, it is highly likely that interaction of viruses with key molecules in host cell metabolic pathways, including energy-generating systems, contributes to the virus replication. In the previous study, the ATP level in NNV-infected cells was lower than that in non-infected cells; that means that NNV replication depleted host ATP [25]. Mitochondrial creatine kinase (MtCK), adenine nucleotide translocase (ANT), and VDAC2 formed a complex in humans [65]. In the IP interaction database, the proteins that participated in ATP generation, such as $\mathrm{ADP} / \mathrm{ATP}$ translocase, CK, VDAC1, and VDAC2, were verified. In order to verify that the interaction of NNV with cellular molecule of ATP generation pathway contributes to virus amplification, and also to confirm that the reliability of our IP results is very high, we chose $\mathrm{CK}$ for subsequent analysis. $\mathrm{CK}$ catalyzes the reversible transfer of the phosphate group of phosphocreatine ( $\mathrm{pCr}$ ) to ADP to yield ATP and creatine and is known to play important roles in local delivery and cellular compartmentalization of ATP [66]. CK also plays an important role in tissues that require a lot of energy, such as muscle, optic nerve, and brain, in which the brain and optic nerve are the major infectious tissue of NNV [67]. Furthermore, VDAC2 is required for NNV infection for maintaining the cellular ATP level and has a positive regulate on virus-induced apoptosis [25]. Since VDAC2 has been shown required when NNV infection, and based on the indirect relationship between VDAC2/CK/NNVCP, we further validate the interaction relationship between CK and NNVCP. The CKB-NNVCP complex was clearly detected in vitro using anti-Ckba antibody in far-Western blot assay (Figure 3D), and the in vivo immunostaining assay revealed that CK was colocalized with NNVCP (Figure 4B). In addition, we demonstrated that the presence of CKB could enhance NNV replication (Figure 6). Therefore, we concluded that 
$\mathrm{NNVCP}$, through its interaction with $\mathrm{CKB}$, controls the generation of ATP in the host cell to enhance virus replication.

In summary, in this research, according to IP experiment data, we first identified 49 grouper optic nerve proteins involved in NNV morphogenesis by interacting with NNVCP. In NNV-infected tissue, CKB gene expression was upregulated; meanwhile, NNV replicate will enhance by interacting with CKB. Here, CKB was identified as a novel enhancer for NNV through interact with NNVCP. Our findings would be beneficial to extend to an understanding of the host cell response and morphogenesis of NNV. This may lead to the development of a new type of antiviral agent.

Author Contributions: Conceptualization, P.-Y.H. and L.-L.C.; investigation, H.-C.H., S.-W.W., S.-F.L. and M.-W.L.; validation, P.-Y.H. and L.-L.C.; writing-original draft preparation, P.-Y.H. and L.-L.C; writing-review and editing, P.-Y.H. and L.-L.C. All authors have read and agreed to the published version of the manuscript.

Funding: Ministry of Science and Technology, Taiwan: MOST 106-2313-B-019-005-MY3.

Acknowledgments: This investigation was supported financially by the Ministry of Science and Technology (MOST 106-2313-B-019-005-MY3). This work was also supported by grants from the Center of Excellence for the Oceans (National Taiwan Ocean University), which is financially supported by The Featured Areas Research Center Program within the framework of the Higher Education Sprout Project by the Ministry of Education in Taiwan, ROC.

Conflicts of Interest: The authors declare no conflict of interest.

\section{References}

1. Hegde, A.; Chen, C.; Qin, Q.; Lam, T.; Sin, Y. Characterization, pathogenicity and neutralization studies of a nervous necrosis virus isolated from grouper, Epinephelus tauvina, in Singapore. Aquaculture 2002, 213, 55-72. [CrossRef]

2. Qin, Q.; Chang, S.; Ngoh-Lim, G.; Gibson-Kueh, S.; Shi, C.; Lam, T. Characterization of a novel ranavirus isolated from grouper Epinephelus tauvina. Dis. Aquat. Org. 2003, 53, 1-9. [CrossRef] [PubMed]

3. Wei, J.; Huang, Y.; Zhu, W.; Li, C.; Huang, X.; Qin, Q. Isolation and identification of Singapore grouper iridovirus Hainan strain (SGIV-HN) in China. Arch. Virol. 2019, 164, 1869-1872. [CrossRef] [PubMed]

4. Bandín, I.; Souto, S. Betanodavirus and VER disease: A 30-year research review. Pathogens 2020, 9, 106. [CrossRef]

5. Arimoto, M.; Maruyama, K.; Furusawa, I. Epizootiology of viral nervous necrosis (VNN) in striped jack. Fish Pathol. 1994, 29, 19-24. [CrossRef]

6. Munday, B.; Kwang, J.; Moody, N. Betanodavirus infections of teleost fish: A review. J. Fish Dis. 2002, 25, 127-142. [CrossRef]

7. Kara, H.; Chaoui, L.; Derbal, F.; Zaidi, R.; De Boisséson, C.; Baud, M.; Bigarré, L. Betanodavirus-associated mortalities of adult wild groupers E pinephelus marginatus (Lowe) and E pinephelus costae (Steindachner) in A lgeria. J. Fish Dis. 2014, 37, 273-278. [CrossRef]

8. Moody, N.; Horwood, P.; Reynolds, A.; Mahony, T.; Anderson, I.; Oakey, H. Phylogenetic analysis of betanodavirus isolates from Australian finfish. Dis. Aquat. Org. 2009, 87, 151-160. [CrossRef]

9. Vendramin, N.; Patarnello, P.; Toffan, A.; Panzarin, V.; Cappellozza, E.; Tedesco, P.; Terlizzi, A.; Terregino, C.; Cattoli, G. Viral Encephalopathy and Retinopathy in groupers (Epinephelus spp.) in southern Italy: A threat for wild endangered species? BMC Vet. Res. 2013, 9, 1-7. [CrossRef]

10. Costa, J.Z.; Thompson, K.D. Understanding the interaction between Betanodavirus and its host for the development of prophylactic measures for viral encephalopathy and retinopathy. Fish Shellfish Immunol. 2016, 53, 35-49. [CrossRef]

11. Chi, S.; Lo, C.; Kou, G.; Chang, P.; Peng, S.; Chen, S. Mass mortalities associated with viral nervous necrosis $(\mathrm{VNN})$ disease in two species of hatchery-reared grouper, Epinephelus fuscogutatus and Epinephelus akaara (Temminck \& Schlegel). J. Fish Dis. 1997, 20, 185-193.

12. Mori, K.-I.; Nakai, T.; Muroga, K.; Arimoto, M.; Mushiake, K.; Furusawa, I. Properties of a new virus belonging to Nodaviridae found in larval striped jack (Pseudocaranx dentex) with nervous necrosis. Virology 1992, 187, 368-371. [CrossRef]

13. Chen, L.-J.; Su, Y.-C.; Hong, J.-R. Betanodavirus non-structural protein B1: A novel anti-necrotic death factor that modulates cell death in early replication cycle in fish cells. Virology 2009, 385, 444-454. [CrossRef] 
14. Fenner, B.J.; Thiagarajan, R.; Chua, H.K.; Kwang, J. Betanodavirus B2 is an RNA interference antagonist that facilitates intracellular viral RNA accumulation. J. Virol. 2006, 80, 85-94. [CrossRef] [PubMed]

15. Iwamoto, T.; Mise, K.; Takeda, A.; Okinaka, Y.; Mori, K.-I.; Arimoto, M.; Okuno, T.; Nakai, T. Characterization of Striped jack nervous necrosis virus subgenomic RNA3 and biological activities of its encoded protein B2. J. Gen. Virol. 2005, 86, 2807-2816. [CrossRef] [PubMed]

16. Liu, H.; Teng, Y.; Zheng, X.; Wu, Y.; Xie, X.; He, J.; Ye, Y.; Wu, Z. Complete sequence of a viral nervous necrosis virus (NNV) isolated from red-spotted grouper (Epinephelus akaara) in China. Arch. Virol. 2012, 157, 777-782. [CrossRef]

17. Iwamoto, T.; Okinaka, Y.; Mise, K.; Mori, K.-I.; Arimoto, M.; Okuno, T.; Nakai, T. Identification of host-specificity determinants in betanodaviruses by using reassortants between striped jack nervous necrosis virus and sevenband grouper nervous necrosis virus. J. Virol. 2004, 78, 1256-1262. [CrossRef]

18. Nishizawa, T.; Furuhashi, M.; Nagai, T.; Nakai, T.; Muroga, K. Genomic classification of fish nodaviruses by molecular phylogenetic analysis of the coat protein gene. Appl. Environ. Microbiol. 1997, 63, 1633-1636. [CrossRef]

19. Kuan, Y.C.; Sheu, F.; Lee, G.C.; Tsai, M.W.; Hung, C.L.; Nan, F.H. Administration of recombinant Reishi immunomodulatory protein (rLZ-8) diet enhances innate immune responses and elicits protection against nervous necrosis virus in grouper Epinephelus coioides. Fish Shellfish Immunol. 2012, 32, 986-993. [CrossRef]

20. Wang, Y.D.; Rajanbabu, V.; Chen, J.Y. Transcriptome analysis of medaka following epinecidin-1 and TH1-5 treatment of NNV infection. Fish Shellfish Immunol. 2015, 42, 121-131. [CrossRef]

21. Kuo, H.P.; Chung, C.L.; Hung, Y.F.; Lai, Y.S.; Chiou, P.P.; Lu, M.W.; Kong, Z.L. Comparison of the responses of different recombinant fish type I interferons against betanodavirus infection in grouper. Fish Shellfish Immunol. 2016, 49, 143-153. [CrossRef] [PubMed]

22. Lomonossoff, G.P.; Marsian, J.; Hurdiss, D.L.; Ranson, N.A.; Ritala, A.; Paley, R.K.; Cano Cejas, I. Plant-made nervous necrosis virus-like particles protect fish against disease. Front. Plant Sci. 2019, 10, 880.

23. Chang, J.S.; Chi, S.C. GHSC70 is involved in the cellular entry of nervous necrosis virus. J. Virol. 2015, 89, 61-70. [CrossRef] [PubMed]

24. Zhang, W.; Jia, K.; Jia, P.; Xiang, Y.; Lu, X.; Liu, W.; Yi, M. Marine medaka heat shock protein 90ab1 is a receptor for red-spotted grouper nervous necrosis virus and promotes virus internalization through clathrin-mediated endocytosis. PLoS Pathog. 2020, 16, e1008668. [CrossRef]

25. Chang, J.S.; Chi, S.C. Grouper voltage-dependent anion selective channel protein 2 is required for nervous necrosis virus infection. Fish Shellfish Immunol. 2015, 46, 315-322. [CrossRef]

26. Liu, H.; Sadygov, R.G.; Yates, J.R., 3rd. A model for random sampling and estimation of relative protein abundance in shotgun proteomics. Anal. Chem. 2004, 76, 4193-4201. [CrossRef]

27. Chen, K.Y.; Hsu, T.C.; Huang, P.Y.; Kang, S.T.; Lo, C.F.; Huang, W.P.; Chen, L.L. Penaeus monodon chitin-binding protein (PmCBP) is involved in white spot syndrome virus (WSSV) infection. Fish Shellfish Immunol. 2009, 27, 460-465. [CrossRef]

28. Manos, P.; Edmond, J. Immunofluorescent analysis of creatine kinase in cultured astrocytes by conventional and confocal microscopy: A nuclear localization. J. Comp. Neurol. 1992, 326, 273-282. [CrossRef]

29. Valero, Y.; Arizcun, M.; Esteban, M.Á.; Cuesta, A.; Chaves-Pozo, E. Transcription of histones H1 and H2B is regulated by several immune stimuli in gilthead seabream and European sea bass. Fish Shellfish Immunol. 2016, 57, 107-115. [CrossRef]

30. Wu, Y.; Chi, S. Cloning and analysis of antiviral activity of a barramundi (Lates calcarifer) Mx gene. Fish Shellfish Immunol. 2007, 23, 97-108. [CrossRef]

31. Zou, J.; Secombes, C.J. Teleost fish interferons and their role in immunity. Dev. Comp. Immunol. 2011, 35, 1376-1387. [CrossRef] [PubMed]

32. Leong, J.A.C.; Trobridge, G.D.; Kim, C.H.; Johnson, M.; Simon, B. Interferon-inducible Mx proteins in fish. Immunol. Rev. 1998, 166, 349-363. [CrossRef] [PubMed]

33. Chen, Y.-M.; Su, Y.-L.; Shie, P.-S.; Huang, S.-L.; Yang, H.-L.; Chen, T.-Y. Grouper Mx confers resistance to nodavirus and interacts with coat protein. Dev. Comp. Immunol. 2008, 32, 825-836. [CrossRef]

34. Guerrero, C.A.; Bouyssounade, D.; Zárate, S.; Iša, P.; López, T.; Espinosa, R.; Romero, P.; Méndez, E.; López, S.; Arias, C.F. Heat shock cognate protein 70 is involved in rotavirus cell entry. J. Virol. 2002, 76, 4096-4102. [CrossRef] 
35. Saphire, A.C.; Guan, T.; Schirmer, E.C.; Nemerow, G.R.; Gerace, L. Nuclear import of adenovirus DNA in vitro involves the nuclear protein import pathway and hsc70. J. Biol. Chem. 2000, 275, 4298-4304. [CrossRef] [PubMed]

36. Agostini, I.; Popov, S.; Li, J.; Dubrovsky, L.; Hao, T.; Bukrinsky, M. Heat-shock protein 70 can replace viral protein R of HIV-1 during nuclear import of the viral preintegration complex. Exp. Cell Res. 2000, 259, 398-403. [CrossRef] [PubMed]

37. Hu, J.; Seeger, C. Hsp90 is required for the activity of a hepatitis B virus reverse transcriptase. Proc. Natl. Acad. Sci. USA 1996, 93, 1060-1064. [CrossRef]

38. Stahl, M.; Retzlaff, M.; Nassal, M.; Beck, J. Chaperone activation of the hepadnaviral reverse transcriptase for template RNA binding is established by the Hsp70 and stimulated by the Hsp90 system. Nucleic Acids Res. 2007, 35, 6124-6136. [CrossRef]

39. Park, S.G.; Jung, G. Human hepatitis B virus polymerase interacts with the molecular chaperonin Hsp60. J. Virol. 2001, 75, 6962-6968. [CrossRef]

40. Cripe, T.P.; Delos, S.E.; Estes, P.A.; Garcea, R.L. In vivo and in vitro association of hsc70 with polyomavirus capsid proteins. J. Virol. 1995, 69, 7807-7813. [CrossRef]

41. Crouchet, E.; Baumert, T.F.; Schuster, C. Hepatitis C virus-apolipoprotein interactions: Molecular mechanisms and clinical impact. Expert REV Proteomic 2017, 14, 593-606. [CrossRef] [PubMed]

42. Ku, N.O.; Zhou, X.; Toivola, D.M.; Omary, M.B. The cytoskeleton of digestive epithelia in health and disease. Am. J. Physiol. 1999, 277, G1108-G1137. [CrossRef] [PubMed]

43. Fuchs, E.; Weber, K. Intermediate filaments: Structure, dynamics, function, and disease. Annu. Rev. Biochem. 1994, 63, 345-382. [CrossRef] [PubMed]

44. Zhong, Q.; An, X.; Yang, Y.X.; Hu, H.D.; Ren, H.; Hu, P. Keratin 8 is involved in hepatitis B virus replication. J. Med. Virol. 2014, 86, 687-694. [CrossRef]

45. Bar, H.; Fischer, D.; Goudeau, B.; Kley, R.A.; Clemen, C.S.; Vicart, P.; Herrmann, H.; Vorgerd, M.; Schroder, R. Pathogenic effects of a novel heterozygous R350P desmin mutation on the assembly of desmin intermediate filaments in vivo and in vitro. Hum. Mol. Genet. 2005, 14, 1251-1260. [CrossRef]

46. Vassar, R.; Coulombe, P.A.; Degenstein, L.; Albers, K.; Fuchs, E. Mutant keratin expression in transgenic mice causes marked abnormalities resembling a human genetic skin disease. Cell 1991, 64, 365-380. [CrossRef]

47. Richens, J.L.; Spencer, H.L.; Butler, M.; Cantlay, F.; Vere, K.A.; Bajaj, N.; Morgan, K.; O’Shea, P. Rationalising the role of Keratin 9 as a biomarker for Alzheimer's disease. Sci. Rep. 2016, 6, 22962. [CrossRef]

48. Neilson, D.E.; Adams, M.D.; Orr, C.M.; Schelling, D.K.; Eiben, R.M.; Kerr, D.S.; Anderson, J.; Bassuk, A.G.; Bye, A.M.; Childs, A.-M. Infection-triggered familial or recurrent cases of acute necrotizing encephalopathy caused by mutations in a component of the nuclear pore, RANBP2. Am. J. Hum. Genet. 2009, 84, 44-51. [CrossRef]

49. Woo, J.; Jung, A.; Lakshmana, M.; Bedrossian, A.; Lim, Y.; Bu, J.; Park, S.; Koo, E.; Mook-Jung, I.; Kang, D. Pivotal role of the RanBP9-cofilin pathway in A $\beta$-induced apoptosis and neurodegeneration. Cell Death Differ. 2012, 19, 1413. [CrossRef]

50. Liu, T.; Roh, S.; Woo, J.; Ryu, H.; Kang, D. Cooperative role of RanBP9 and P73 in mitochondria-mediated apoptosis. Cell Death Dis. 2013, 4, e476. [CrossRef]

51. Grünblatt, E.; Riederer, P. Aldehyde dehydrogenase (ALDH) in Alzheimer's and Parkinson's disease. J. Neural. Transm. 2016, 123, 83-90. [CrossRef] [PubMed]

52. Li, D.; Dong, H.; Li, S.; Munir, M.; Chen, J.; Luo, Y.; Sun, Y.; Liu, L.; Qiu, H.J. Hemoglobin subunit beta interacts with the capsid protein and antagonizes the growth of classical swine fever virus. J. Virol. 2013, 87, 5707-5717. [CrossRef] [PubMed]

53. Fuchs, D.; Zangerle, R.; Artner-Dworzak, E.; Weiss, G.; Fritsch, P.; Tilz, G.P.; Dierich, M.P.; Wachter, H. Association between immune activation, changes of iron metabolism and anaemia in patients with HIV infection. Eur. J. Haematol. 1993, 50, 90-94. [CrossRef] [PubMed]

54. Nishizawa, T.; Takano, R.; Muroga, K. Mapping a neutralizing epitope on the coat protein of striped jack nervous necrosis virus. J. Gen. Virol. 1999, 80 Pt 11, 3023-3027. [CrossRef]

55. Bravo, R.; Parra, V.; Gatica, D.; Rodriguez, A.E.; Torrealba, N.; Paredes, F.; Wang, Z.V.; Zorzano, A.; Hill, J.A.; Jaimovich, E.; et al. Endoplasmic reticulum and the unfolded protein response: Dynamics and metabolic integration. Int. Rev. Cell Mol. Biol. 2013, 301, 215-290. [CrossRef] 
56. Wu, Y.M.; Hsu, C.H.; Wang, C.H.; Liu, W.; Chang, W.H.; Lin, C.S. Role of the DxxDxD motif in the assembly and stability of betanodavirus particles. Arch. Virol. 2008, 153, 1633-1642. [CrossRef]

57. Chin, D.; Means, A.R. Calmodulin: A prototypical calcium sensor. Trends Cell Biol. 2000, 10, 322-328. [CrossRef]

58. Yamniuk, A.P.; Vogel, H.J. Calmodulin's flexibility allows for promiscuity in its interactions with target proteins and peptides. Mol. Biotechnol. 2004, 27, 33-57. [CrossRef]

59. Dreux, M.; Chisari, F.V. Viruses and the autophagy machinery. Cell Cycle Georget. Tex. 2010, 9, $1295-1307$. [CrossRef]

60. Vlach, J.; Samal, A.B.; Saad, J.S. Solution structure of calmodulin bound to the binding domain of the HIV-1 matrix protein. J. Biol. Chem. 2014, 289, 8697-8705. [CrossRef]

61. Jin, Y.; Zhang, R.; Wu, W.; Duan, G. Antiviral and Inflammatory Cellular Signaling Associated with Enterovirus 71 Infection. Viruses 2018, 10, 155. [CrossRef] [PubMed]

62. Lehmann, M.J.; Sherer, N.M.; Marks, C.B.; Pypaert, M.; Mothes, W. Actin- and myosin-driven movement of viruses along filopodia precedes their entry into cells. J. Cell Biol. 2005, 170, 317-325. [CrossRef] [PubMed]

63. Sasaki, H.; Nakamura, M.; Ohno, T.; Matsuda, Y.; Yuda, Y.; Nonomura, Y. Myosin-actin interaction plays an important role in human immunodeficiency virus type 1 release from host cells. Proc. Natl. Acad. Sci. USA 1995, 92, 2026-2030. [CrossRef] [PubMed]

64. Ye, T.; Zong, R.; Zhang, X. Involvement of interaction between viral VP466 and host tropomyosin proteins in virus infection in shrimp. Gene 2012, 505, 254-258. [CrossRef]

65. Dolder, M.; Wendt, S.; Wallimann, T. Mitochondrial creatine kinase in contact sites: Interaction with porin and adenine nucleotide translocase, role in permeability transition and sensitivity to oxidative damage. Biol. Signals Recept. 2001, 10, 93-111. [CrossRef]

66. Wallimann, T.; Wyss, M.; Brdiczka, D.; Nicolay, K.; Eppenberger, H. Intracellular compartmentation, structure and function of creatine kinase isoenzymes in tissues with high and fluctuating energy demands: The 'phosphocreatine circuit'for cellular energy homeostasis. Biochem. J. 1992, 281, 21-40. [CrossRef]

67. Megarajan, S.; Ranjan, R.; Xavier, B.; Ghosh, S.; Sadu, N.; Bathina, C.; Gopalakrishnan, A. Molecular detection of betanodavirus in orange-spotted grouper (Epinephelus coioides) broodstock maintained in recirculating aquaculture systems and sea cages. Aquac. Int. 2020, 349-362. [CrossRef]

(C) 2020 by the authors. Licensee MDPI, Basel, Switzerland. This article is an open access article distributed under the terms and conditions of the Creative Commons Attribution (CC BY) license (http://creativecommons.org/licenses/by/4.0/). 